REVUE

\title{
Études sur les pâturages et les aliments du bétail dans les pays tropicaux et subtropicaux
}

(Suite)

par M.-G. CURASSON

\section{FRUITS, GRAINES ET IEURS SOUS-PRODUITS}

(Suite)

\section{CONIFÈRES \\ Genre Juniperus}

Divers « Genevriers 》, buissons de régions arides d'Asie ou d'Amérique, voient leurs fruits mangés par les animaux. C'est ainsi que dans le Baluchistan, les chameaux de labour mangent les baies de Juniperus sp. qu'on leur distribue parfois.

Dans le Texas, le peuplement exagéré de certains pâturages a amené l'invasion de vastes zones par divers Juniperus : J. mexicana, J. virginiana, J. pinchotia. Les fruits de ces espèces sont mangés. La composition de ceux de la dernière espèce est :

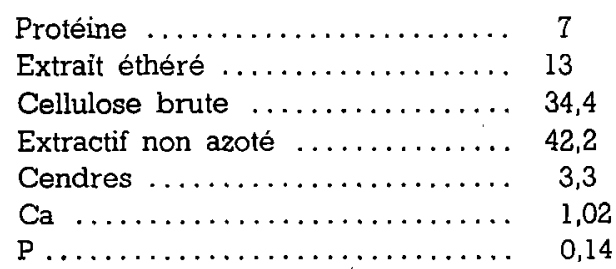

\section{Genre Araucaria}

Les grands arbres de ce genre, en régions chaudes de l'Amérique du Sud (Argentine) ont des cônes, fruits qu'on destine au bétail : Araucaria angustifolia, A. araucana.

\section{CORDIACÉES}

\section{Genre Persea}

Les arbres de ce genre, originaires de l'Inde, comprennent l'arbre aux sébestes, à fruits mucilagineux. Au Mexique, au Brésil, tous les animaux mangent les fruits - surtout la pulpe - de Persea americana et $P$, gratissima.

\section{CORNACEES \\ Genre Cornus}

Nous avons vu que les feuilles de diverses espèces du genre, dans les régions semi-tropicales, sont volontiers mangées par les animaux. Les fruits ont eux aussi leur valeur. Voici la composition de ceux de deux espèces américaines.

$\begin{array}{lllllllll} & & \text { Eau } & \text { Protéine } & \text { Graisse } & \text { Cellulose H.deC. Cendres } \\ \text { Cornus femina } & . . & 57 & 6,9 & 26,7 & 25,8 & 37,3 & 3,4 \\ \text { Cornus stolonifera. } & 68,4 & 6,9 & 12 & 26,4 & 51,2 & 3,4\end{array}$

\section{CORYNOCARPACEES}

\section{Genre Corynocarpus}

Corynocarpus loevigata, arbre de Nouvelle Zélande qui fournit au bétail ses longues feuilles, a un fruit avec un noyau dont les Maoris tirent en le traitant pour lui enlever son pouvoir toxique. une farine alimentaire. Ce noyau, en effet, contient une substance cyanogénétique qui disparaît au chauffage. Le noyau cru n'est d'ailleurs que peu dangereux pour le porc et le bœuf, alors qu'il l'est beaucoup plus pour l'homme et le chien. Les deux parties du fruit, pulpe et noyau, ont la composition suivante :

\begin{tabular}{|c|c|c|c|}
\hline Protéine & Graisse Ext. & non azoté & Cendre \\
\hline 8,8 & " & 40,5 & 8,3 \\
\hline 14,6 & 13,6 & 56,4 & 6,4 \\
\hline \multicolumn{4}{|c|}{ CRUCIFËRES } \\
\hline Genre & Brassica & $!$ & \\
\hline
\end{tabular}

Des diverses espèces du genre cultivées dans l'Inde, on utilise la graine pour la production d'huile. Le résidu constitue des tourteaux qu'on donne aux 
animaux : $B$. napus, $B$. juncea notamment; le tourteau de la dernière espèce renferme :

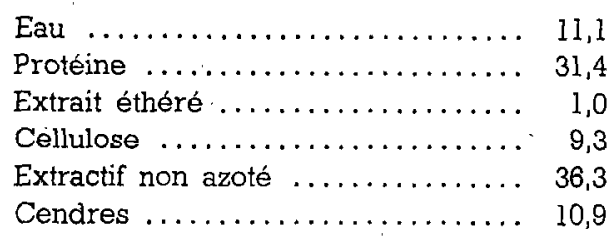

\section{Genre Carthamus}

Les graines de Carthamus indicus sont rarement distribuées. C'est le tourteau qui, après extraction de l'huile, est donné aux animaux.

La graine non décortiquée, a la composition suivante :

$\begin{array}{llr}\text { Eau } \ldots \ldots \ldots \ldots \ldots \ldots \ldots \ldots \ldots & 6,58 \\ \text { Proténe brute } \ldots \ldots \ldots \ldots \ldots \ldots & 13,65 \\ \text { Extrait éthéré } \ldots \ldots \ldots \ldots \ldots \ldots \ldots & 25,67 \\ \text { Cellulose } \ldots \ldots \ldots \ldots \ldots \ldots \ldots \ldots & 29,53 \\ \text { Extractif non azoté } \ldots \ldots \ldots \ldots \ldots \ldots & 20,40 \\ \text { Cendres } \ldots \ldots \ldots \ldots \ldots \ldots \ldots \ldots & 4,17\end{array}$

Le tourteau, décortiqué ou non, a la composition suivante :

\begin{tabular}{|c|c|c|}
\hline & décortiqué & non décortique \\
\hline Eau & 11,60 & 8,55 \\
\hline Protéine brute.. & 47,88 & 20,55 \\
\hline Extrait éthéré . & 7,70 & 9,73 \\
\hline Cellulose brute . & 6,20 & 32,95 \\
\hline Extractif non azoté $\ldots \ldots \ldots$ & 19,72 & 25,12 \\
\hline Cendres $\ldots \ldots \ldots \ldots \ldots \ldots$ & 3,40 & 16,15 \\
\hline \multicolumn{3}{|l|}{ Une autre analyse donne } \\
\hline Eau & & 7,6 \\
\hline Protéine & & 32,1 \\
\hline Graisse $\ldots \ldots \ldots \ldots$ & & 12 \\
\hline Cendres $\ldots \ldots \ldots \ldots \ldots$ & $\ldots \ldots$ & 4,1 \\
\hline Ca $\ldots \ldots \ldots \ldots \ldots$ & $\ldots$ & 0,075 \\
\hline$P \ldots$ & & 0,62 \\
\hline & & 0,63 \\
\hline
\end{tabular}

L'addition de $10 \mathrm{p}, 100$ de ce tourteau à une ration pauvre (riz) accélère la croissance chez les rats; la valeur biologique de la protéine est grande.

\section{CUCURBITACÉES}

Diverses espèces sauvages de cette famille ont des fruits que mangent les animaux et qui sont souvent un bon appoint, en saison sèche, en raison de leur teneur en eau(Cephalendra spp., Cnucumis spp.).

C'est le cas pour diverses espèces saheliennes dénommées cancani, parfois abondantes sur les terrains dénudés, et que les animaux recherchent malgré leur saveur amere.
Une cucurbitacée asiatique voisine, Momordica cochinchinensis a des fruits de couleur orange moyennement riches en carotène.

Acanthocysies horrida, le melon du Calahari, est une plante interessante des zones désertiques qui a été essayée en diverses régions africaines. Les racines, qui vont à 30 mètres, lui permettent de résister pendant trois années sans pluies, et de donner de nombreux "melons " appréciés de l'hornme et des animaux; le jus, aqueux et sucré, sert aux animaux de nourriture et de boisson.

On cultive en régions chaudes, même en régions sèches en profitant de la saison des pluies, diverses citrouilles, pastèques, "melons d'eau ", ctc., qui sont de bons aliments aqueux en saison sèche. On les conserve assez longtemps, à l'abri, en séparant les fruits par de la paille, des tiges de mil, etc.

Deux analyses de Citrullus vulgaris, en Europe, domnent les résultals suivants

\begin{tabular}{|c|c|}
\hline Matière sèche. & et 7,6 \\
\hline Protéine .... & 0,9 et 0,43 \\
\hline Graisse $\ldots \ldots \ldots$ & 0,2 et 0,2 \\
\hline $\begin{array}{l}\text { Extractif non azoté. } \\
\text { Cellulose }\end{array}$ & 6,3 et $》$ \\
\hline
\end{tabular}

En Afrique du Sud, on donne les chiffres suivants :

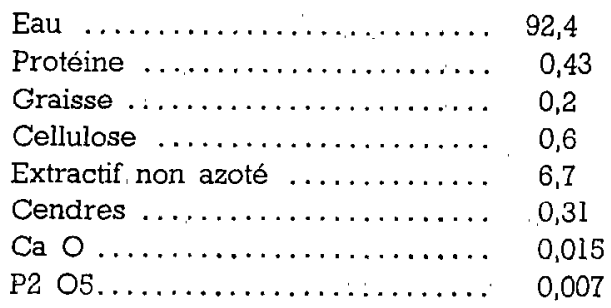

La composition moyenne de divers cucurbita d'Amérique est :

Eau $\ldots \ldots \ldots \ldots \ldots, 77$ à $87 \%$

Protéine .......... 1,1 à 1,9

Sucres ............ 0,5 à 4,23

Carotène .......... 0,9 à $8,5 \mathrm{mg}$ pour $100 \mathrm{~g}$

Acide ascorbique ... 3,4 à $39 \quad \mathrm{mg} \quad \mathrm{d}^{\circ}$

$\mathrm{Ca} \ldots \ldots \ldots \ldots \ldots$ is à 31

$P \ldots \ldots \ldots \ldots \ldots, 23$ à 55

Dans plusieurs régions africaines, et particulièrement en Afrique occidentale, les graines de Citrullus vulgaris (beref au Sénégal) sont employées à la fabrication d'une huile alimentaire. Le tourteau ou plutôt la pulpe résiduelle (car il ne s'agit pas d'un vrai tourteau, l'extraction se faisant par chauffage au-dessus d'eau bouillante) est riche en huile, donc facilement altérable, et aussi en azote, d'où l'indication de le donner avec des aliments hydrocarbonés. 
Une analyse d'un produit sénégalais donne

\begin{tabular}{|c|c|}
\hline 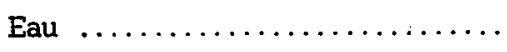 & $8,55 \%$ \\
\hline Protéine & 28,05 \\
\hline Graisse . & 7,89 \\
\hline Cellulose........ & 28,35 \\
\hline Extractif non azoté $\ldots \ldots \ldots \ldots \ldots$ & 20,90 \\
\hline Cendres $\ldots \ldots \ldots \ldots \ldots \ldots \ldots \ldots$ & 6,24 \\
\hline
\end{tabular}

Des graines non traitées donnent les chiffres suivants :

\begin{tabular}{lcc} 
& \multicolumn{3}{c}{ Soudan égyptien } & Sierra Leone \\
Eau $\ldots \ldots \ldots \ldots \ldots \ldots \ldots$ & 7,4 & 7,1 \\
Protéine $\ldots \ldots \ldots \ldots \ldots \ldots$ & 14 & 34,3 \\
Extractif éthéré $\ldots \ldots \ldots \ldots$ & 23,6 & 44,4 \\
Cellulose $\ldots \ldots \ldots \ldots \ldots$ & 32,2 & 6,7 \\
Extrait non azoté $\ldots \ldots \ldots$ & 20,6 & 4,8 \\
Cendres $\ldots \ldots \ldots \ldots \ldots$ & 2,7 & 2,9
\end{tabular}

Les " graines " de Cucamis Chate (" senet-fruit 》) du Soudan égyptien renferment :

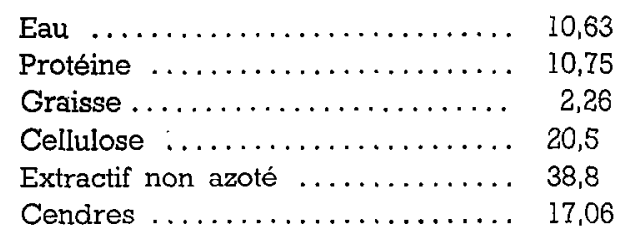

La pulpe résiduelle, de diverses origines, comparativement au produit sénégalais, a une composition assez variée, surtout en protéine, ainsi que le montrent les chiffres suivants pour cinq échantillons

- du Soudan, de Sierra Leone et de Gold Coast.

\begin{tabular}{|c|c|c|c|c|c|}
\hline & 1 & 2 & 3 & 4 & 5 \\
\hline & 一 & - & 一 & - & - \\
\hline & 9,5 & 10,1 & 9,7 & 10,6 & 9,2 \\
\hline Protéine brute. & 18,3 & 35,3 & 28,2 & 62,8 & 42,6 \\
\hline Extrait éthéré & 5 & 7 & 7 & 6 & 9 \\
\hline Cellulose.... & 41,9 & 29 & 39,2 & 12,2 & 31,9 \\
\hline xtractif non azoté & 26,9 & 14,3 & 11,3 & 8,9 & 11,2 \\
\hline ndres & 2,9 & $-4,3$ & 4,6 & 4,9 & \\
\hline
\end{tabular}

On n'a pas de renseignements sur la teneur en acides aminés et en vitamines.

\section{Genre Sechium}

Sechium edule (chayotte) est une cucurbitacée grimpante vivace qui donne une récolte abondante de fruits du volume d'une orange. Dans plusieurs pays d'Amérique du Sud, ces fruits sont mangés volontiers par tous les animaux, et on considère que leur valeur avoisine celle du manioc et de la patate douce.

(La racine est également distribuée, ainsi que les feuilles, qu'on ensile parfois.)

\section{Genre Telfairia}

Les graines de plusieurs espèces sont comestibles. L'une d'elles le "Koueme " de la Réunion, donne une bonne huile. C'est Telfairia pedeta dont les graines renferment :

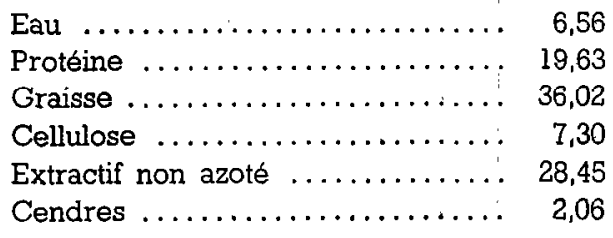

Le tourteau a été utilisé au Congo belge.

\section{Genres divers}

A côté des espèces comestibles, il en est d'autres qui peuvent être dangereuses : Cucumis myriocarpus, C. africanus, C. leptodermis, Citrullus colocinthis, Cucurbita maxima. En Afrique du Sud, Melathria punctata, mangée en saison sèche, est toxique surtout par ses fruits.

\section{DILLNIACÉES \\ Genre Tetracarpidium}

Tetracarpidium conophorum, d'Afrique occidentale, a des amandes qui, après extraction de l'huile, donnent un tourteau dont la teneur en protéine est sensiblement la même que celle' du tourteau d'arachide décortiqué. Sa valeur alimentaire est au moins égale chez la vache laitière. Chez le porc, il est avantageux de l'utiliser dans la proportion de 10 p. 100 de la ration.

\section{ÉBENACÉES \\ Genre Diospyros}

Diverses espèces de ce genre, africaines et américaines, sont des formes buissonneuses ou arbustives dont les animaux, surtout les moutons et les chèvres, mangent volontiers les feuilles et les fruits, ces derniers ayant une pulpe sucrée.

D. mespiliformis, le "sounsoun 》 de l'Afrique occidentale, (surtout la zone sahélienne) a une pulpe assez volumineuse, très sucrée ( 80 p. 100 d'extractif non azoté). L'amande est riche également.

En Amérique, dans les zones arides, on note $D$. texana, $D$. virginiana. La pulpe du fruit de cette dernière, et l'amande, ont la composition suivante :

Proténe Mat.grasses Cellulose H. de C. Cendres Ca. P.

\begin{tabular}{|c|c|c|c|c|c|c|}
\hline alp & 3,3 & 0,9 & 5,3 & 87,4 & & \\
\hline & 9,6 & 2 & 23,6 & 63 & & \\
\hline
\end{tabular}


C'est au pâturage que les fruits sont mangés. $C$ 'est ainsi que, pour $D$. mespiliformis il arrive que, dans les peuplements importants qu'il constitue. les fruits, drupes du volume d'une petite prune, forment des amas parfois intéressants sous chaque arbuste.

Les moutons de cette zone ingurgitent les fruits puis régurgitent les amandes au moment de la rumination.

Les amandes, concassées, peuvent être distribuées.

\section{EUPHORBIACÉES}

\section{Genre Aleurites}

Les graines de divers Aleurites sont utilisées pour l'obtention d'huiles industrielles. Les tourteaux, de composition variable, renferment en moyenne :

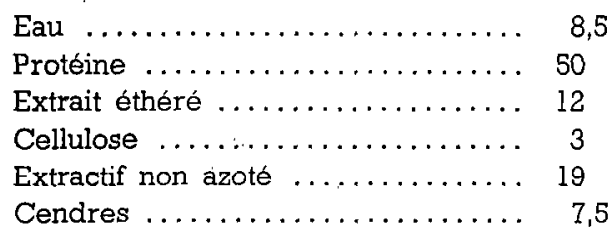

La valeur est inégale, moins en raison des variations de composition que de la présence variable de deux éléments dangereux : une saponine et une substance toxique qu'on peut extraire par l'alcool. Cela explique que les tourteaux d'A. mollucana peuvent être seulement purgatifs et seraient inutilisables pour l'engraissement du bétail (pas chez les vaches laitières parce que la consistance et le goût du beurre seraient affectés) alors que les tourteaux d'A. cordata et $A$. fordii se révèlent toxiques, aussi bien pour les bovins que pour les volailles.

\section{Genre Hevea}

T.es graines de l'arbre à caoutchouc, Hevea brasiliensis, fournissent après extraction de l'huile, un tourieau assez riche : 30 à 34 p. 100 de protéine et 40 à 44 p. 100 d'extractif non azoté. Cela lui confère une valeur voisine de celle du tourteau de lin; il aurait donné de bons résultats chez le mouton et la chèvre.

Cependant il peut être cyanogénétique. Aussi faut-il ne traiter que des graines décortiquées, de plus de six mois, et préparer les aliments à chaud.

\section{ELAEOCARPACEES}

\section{Genre Aristotelia}

Des espèces de ce genre, arbustives, A. racemose, A. serrata, ont des fruits que mangent les opossums, $A$. maqui est une espèce arbustive à fruits comestibles (Chili).

\section{Genre Elaeocarpus}

Deux espèces de ce genre sont de grands arbres de Nouvelle Zelande dont les graines sont volontiers mangées par les porcs, ce qui est favorable à leur engraissement: $E$. dentatus, $E$. hookerianus:

\section{FLACOURTIHCEES}

\section{Genre Oncoba}

Les graines d'Oncoba echinata, d'Afrique occidentale, ont une valeur alimentaire marquée, surtout en raison de leur teneur en graisse :

\begin{tabular}{|c|c|}
\hline $\operatorname{Eau} . .$. & 5,8 à 6 \\
\hline Protéine & 17,5 à 18,1 \\
\hline Graisse & 45 à 46 \\
\hline Cellulose .... & 14,7 à 15,6 \\
\hline Extractif non azoté $\ldots \ldots \ldots \ldots$ & 11,8 à 12,1 \\
\hline Cendres $\ldots \ldots \ldots \ldots \ldots \ldots$ & 2,5 à 2,8 \\
\hline
\end{tabular}

\section{Genre Pangium}

Les graines de Pangium edule, que les volailles mangent à terre (Indonésie) peuvent les intoxiquer.

\section{GNÉTACÉES}

\section{Genre Ephedra}

Plusieurs espèces de ce genre, dans les régions désertiques ou sèches, jouent un rôle intéressant dans l'alimentation du chameau. C'est le cas pour les chameaux qui labourent dans le Baluchistan; ils mangent feuilles et fruits. On retrouve des espèces du genre dans les zones désertiques d'Asie mineure (E. scrobilacea), les zones arides d'Amérique (E. nevadensis). La composition d'E. scrobilacea est la suivante :

$\begin{array}{ll}\text { Protéine brute } \ldots \ldots \ldots \ldots \ldots & 9,2 \text { à } 16,5 \\ \text { Matière grasse } \ldots \ldots \ldots \ldots \ldots & 2,8 \text { à } 3 \\ \text { Cellulose brute } \ldots \ldots \ldots \ldots \ldots & 20,9 \text { à } 37,6 \\ \text { Extractif non azoté } \ldots \ldots \ldots \ldots & 35,3 \text { à } 45,6 \\ \text { Cendres } \ldots \ldots \ldots \ldots \ldots \ldots \ldots & 9 \text { à } 14,8\end{array}$

\section{LAURACEES}

A cette famille appartient l'avocatier, dont le fruit est exceptionnellement donné aux animaux (fruits altérés, verts, etc.).

La teneur du fruit mûr subit les variations suivantes (Nigeria).

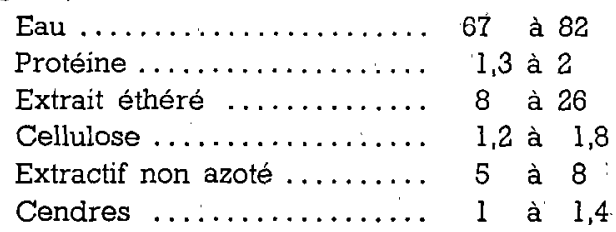

Le fruit est riche en riboflavine (120 ug p. 100). 


\section{Genre Benzoin}

Les espèces de ce genre (Styrax) en Asie et Amérique chaudes peuvent avoir des fruits comestibles. Celui de Benzoin estivale contient :

Protéine ................ 11,9

Extrait éthéré $\ldots \ldots \ldots \ldots \ldots \ldots \ldots$ 50,7

Cellulose ................ 5,2

Extractif non azoté $\ldots \ldots \ldots \ldots \ldots$ 26,4

Cendres .............. 5,7

\section{Genre Cryptocaraya}

Une vingtaine d'arbres de ce genre sont africains (Af. du Sud). Après extraction de l'huile, les graines de Cryptocarya latifolia laissent :

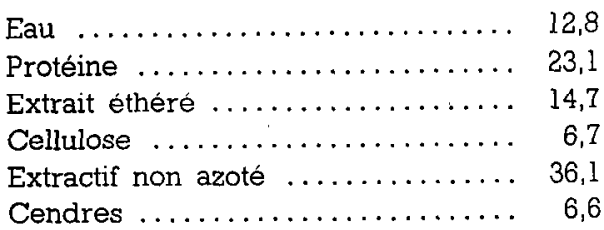

\section{LEUMINEUSES}

Cette famille est particulièrement intéressante par les graines des espèces cultivées. Mais il est aussi des espèces non cultivées dont les fruits, graisses et graines constituent des réserves fourragères importantes.

Les « graines » cultivées sont d'excellents aliments azotés; elles sont données soit entières, soit plus souvent après concassage, aplatissage, trempage, ou en farine. Leur composition varie, surtout en ce qui concerne la matière grasse.

Voici la composition comparée (p. 1.000) de quelques haricots et autres graines de légumineuses utilisées en Indo-Chine pour le cheval et le bcuf.

Mat. azotées Mat. ggrasses Mat. sêche' Nbre de kilogs correspondant à 1 unité

Leucoena glauca . 255

Phaseolus mungo. 145

Phaseolus aureus. 162

Soja.......... 330

Pythecelobium sa-

man (arbre) .... 21

Mucuna utilissima. 210

Arachis hypogea. . 255

Les différences de composition sont beaucoup plus grandes avec les grains de céréales; elles sont particulièrement marquées en ce qui concerne les acides aminés. C'est ainsi que la teneur en arginine de divers graines et grains est la suivante :

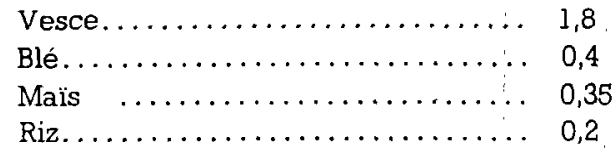

La teneur en choline est également différente entre grains (céréales) et graines (légumineuses). Ainsi, la moyenne pour les céréales' (blé, riz et maïs) est de 0 à 70 ( $\pm 1,8$ ) alors qu'elle est de 99 $( \pm 1,5)$ à 245 ( \pm 4 ) $\mathrm{mg}$ pour $100 \mathrm{~g}$ pour les légumineuses exotiques (Phaseolus radiatus, Cajanus indicus, Cicer arietinum).

En ce qui concerne les graines qui ne sont pas particulièrement oléagineuses, les différences de composition sont souvent minimes pour les éléments moyens

Pois souterrain.

Matières non azotées $\ldots \ldots \ldots \ldots$.... 53,17

Matières azotées ............. 14,11

Matières grasses............. 6,48

Pois d'Angola.

Matières non azotées.......... 62

Matières azotées ............. 20

Matières grasses............ 1,1

Dolique Mongette.

Matières non azotées.......... 57

Matières azotées ............ 23

Matières grasses.............. 1,3

Phaseolus acutifolius.

Matières non azotées............ 65

Matières azotées ............ 28

Matières grasses.............. 1,5

Phaseolus mungo.

Matières non azotées........... 50

Matières azotées $\ldots \ldots \ldots \ldots \ldots \ldots . . .24$

Matières grasses............. 1,4

Canavalia ensiformis.

Matières non azotées........... 48

Matières azotées ............ 26

Matières grasses.............. 2,3

Les différences observées dans les chiffres cidessus sont souvent atténuées par des variations qui ne sont pas spécifiques. Aussi peut-on admettre, comme composition moyenne de ces "haricots" ou «pois » la suivante :

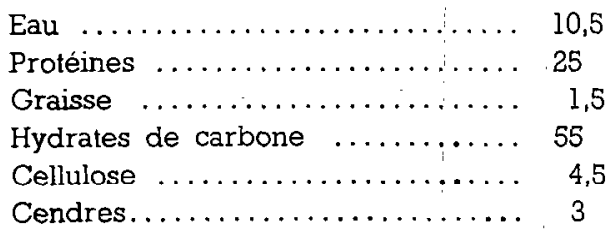




\section{Genre Acacia}

Nous avons précédemment dit l'essentiel concernant la valeur fourragère des Acacias, valeur qui est due pour bonne part aux fruits, gousses et graines, et indiqué pour chaque espèce, le rôle qui revient à chacune des parties de la plante consommée : phyllodes, feuilles, fleurs, fruits. Nous y apportons complément en donnant de nouvelles analyses de gousses et de graines.

\begin{tabular}{|c|c|c|c|c|c|c|c|c|c|}
\hline PRODUIT & Origine & Eau & Protéine & $\begin{array}{l}\text { Extrait } \\
\text { éthéré }\end{array}$ & Cellulose & \begin{tabular}{|} 
Extractif \\
non azoté
\end{tabular} & Cendres & $\mathrm{CaO}$ & P2 05 \\
\hline A. albida gousses. & Rhodésie & 7,1 & 11,1 & 1,4 & 27,5 & 49,5 & 3,4 & - & - \\
\hline A. arabica gousses. & Tanganyika & - & 12,86 & 2,51 & 15,21 & 63,82 & 5,60 & 0,72 & 0,33 \\
\hline A: giraffæ gousses & Rhodésie & - & 12,58 & 1,76 & 34,21 & - & - & 0,99 & 0,26 \\
\hline A: farnesiana gousses. & Queensland & - & 17,2 & 1,6 & 19,4 & 57,1 & 4,1 & 0,55 & 0,20 \\
\hline A. farnesiana graines. & - & 一 & 20,9 & 2,3 & 18,3 & 54,7 & 3,8 & 0,39 & 0,27 \\
\hline A. linophylla gousses. & Mustralie occident. & 一 & 12,8 & 5 & 28,2 & 49,4 & - & 0,31 & 0,15 \\
\hline A.- lifakunensis graines ....... & Afrique du Sud & 一 & 37,8 & 6 & 10,9 & 39,6 & 5,6 & 0,56 & 0,73 \\
\hline $\begin{array}{l}\text { A. litakunerısis, gousses sans } \\
\text { graines } \ldots \ldots \ldots \ldots \ldots \ldots \ldots \ldots\end{array}$ & - & - & 8,7 & 1,6 & 34,3 & 49,4 & 6,2 & 1,10 & 0,19 \\
\hline A. séyal gousses vertes.. & Soudan & 68,5 & 21,3 & 1,8 & 18,6 & 52,2 & 6,1 & 0,98 & 0,43 \\
\hline A. sieberiana fruits ..... & - & - & 11,0 & 1,1 & 24,7 & 59,2 & 4,0 & - & - \\
\hline- & Nigeria & 10,9 & 9,8 & 1,0 & 22,0 & 52,71 & 3,59 & - & 一 \\
\hline A. spirocarpa gousses & Tanganyika & 10,0 & 12,3 & 1,8 & 22,4 & 57,9 & 5,6 & 0,98 & 0,24 \\
\hline A. woodii .. & Rhodésie & - & 8,4 & 0,6 & 25,9 & 57,7 & 7,4 & - & 一 \\
\hline
\end{tabular}

\section{Genre Albizzia}

Nous avons indiqué le rôle fourrager des feuilles et gousses des espèces di1 genre, et la composition des gousses d'Albizzia amara. Voici celle des gousses : d' $A$. basaltica.

Protéine ................... 15,0

Extrait éthéré.............. 4,9

Cellulose ................. 19,7

Extr: non azoté $\ldots \ldots \ldots \ldots \ldots \ldots$. 52,6

Cendres ................... $\quad 7,8$

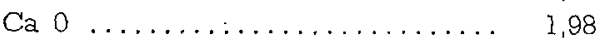

P2 $05 \ldots \ldots \ldots \ldots \ldots \ldots \ldots \ldots, 0,10$

Les graines $d^{\prime} A$. lebbek contiennent :

Protéine ................... 28

Extrait éthéré ................ 3

Cellulose ................. 12

Ëxtr, non azoté $\ldots . \ldots \ldots \ldots \ldots \ldots$....... 53

Cendres .................... 4

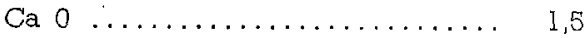

P2 $05 \ldots \ldots \ldots \ldots \ldots \ldots \ldots \ldots \ldots \ldots \ldots \ldots$

\section{Genre Arachis}

La graine d'Arachis hypogea est surtout utilisée après extraction de l'huile, ce qui fournit divers :sous-produits.
On dunne cependant le fruit entier ou on le laisse consommer à maturité par les porcs. On distribue aussi le fruit décortiqué aux vaches latitières ou aux porcs.

En Amérique, on fait pâturer par les porcs quand la graine est à peu près mûre; les animaux déterrent les gousses, et les tiges peuvent être coupées avant, ou livrées au bétail.

Lè principal inconvénient est que le lard obtenu est mou, huileux; on conseille de terminer l'engraissement par le maïs et la graine de coton (7 parties de mais pour une de farine de graines de coton, par exemple).

On nourrit aussi les porcs avec la graine décortiquée. Dans ce cas, l'augmentation de poids est insuffisante si on n'ajoute pas un supplément d'aliments minéraux et de protéines.

L'arachide est parfois incorporée à la ration sous forme de farine, associée aux graines de céréales, notamment pour l'engraissement des bœufs; elle a alors sensiblement la même valeur que la farine de graine de coton. Elle conviendrait cependant mieux, le gain en poids étant plus rapide quand on la donne que lorsqu'on donne la farine de graines de coton en même quantité, bièn que 
l'appétit soit plus grand avec la deuxième. D'autre part, l'huile de la graine aurait pour effet de durcir le beurre.

- Le traitement des graines d'arachide par la chaleur a son influence sur la valeur nutritive; l'expérimentation portant sur des rats montre que le gain moyen, en poids, par gramme de protéine est le suivant : $1,74 \mathrm{~g}$ pour la graine non traitée. $1,84 \mathrm{~g}$ pour la graine bouillie, $1,65 \mathrm{~g}$ pour la graine grillée à $160^{\circ} \mathrm{C}, 0,21 \mathrm{~g}$ seulement pour la graine grillée à $180^{\circ} \mathrm{C}$.

Un inconvénient des graines est que la conservation se heurte à diverses difficultés; cette conservation amène une détérioration des protéines : au bout de 18 mois à $20-30{ }^{\circ} \mathrm{C}$, la perte en protéine dépasse $10 \mathrm{p} .100$ et la digestibilité est diminuée de 8 p. 100. D'autre part, les graines, surtout décortiquées, sont très hygroscopiques et deviennent molles et attaquables par les moisissures; elles sont aussi fréquemment infestées par les larves d'insectes (du genre Plodia dans les Indes, Ephestia tans les pays méditerranéens).
En ce qui concerne la composition, la teneur en protéine est assez peu variable (22 à $28 \mathrm{p}$. 100) la teneur en matière grasse, de 35 à $60 \mathrm{p} .100$.

Les variations tiennent au terrain, à la variété, à l'année, la variété étant le facteur le plus important. Cependant, la teneur en vitamine $\mathrm{Bl}$ et en riboflavine varie surtout avec l'année.

Les protéines de l'arachide comprennent deux globulines : l'arachine et la conarachine, avec les acides aminés essentiels : arginine, histidine, cystine, lysine. Si l'arachine est pauvre en tryptophane et en méthionine, la conarachine apporte ces deux acides aminés; elle est également riche en un acide aminé indispensable : la thréonine:

Comme la plupart des graines oleagineuses, l'arachide est pauvre en vitamines liposolubles; elle renferme peu de vitamines $A$, par contre existent la vitamine $E$ et de l'ergostérol.

La graine est riche en vitamines hydrosolubles B : $B_{1}, B_{2}$, acide pantothénique. C'est une' source riche de vitamines $B_{2}: 3 \mathrm{~g}$ d'arachides renferment autant de vitamines $\mathrm{B}$ que $10 \mathrm{~g}$ de levure de bière, $15 \mathrm{~g}$ de germe de blé et $75 \mathrm{~g}$ de. farine de blé complète.

Analyses d'Arachides de diverses origines

\begin{tabular}{|c|c|c|c|c|c|c|c|c|c|}
\hline Produit & Origine & Eau & Protéine & $\begin{array}{l}\text { Extrait } \\
\text { éthéré }\end{array}$ & Cellulose & $\begin{array}{l}\text { Extractif } \\
\text { non azoté }\end{array}$ & $\begin{array}{l}\text { Cen- } \\
\text { dres }\end{array}$ & $\mathrm{CaO}$ & P2 05 \\
\hline Graine entière & Rhodésie Sud & 7,38 & 24,71 & 36,31 & 16,02 & 13,25 & 2,35 & - & - \\
\hline - & - & 8,82 & 22,07 & 32,09 & 18,12 & 15,45 & 2,64 & :- & - \\
\hline Coques. & - & 10,65 & 4,81 & 0,98 & 61,16 & 19,34 & 3,06 & :- & - \\
\hline - & - & 10,84 & 4,58 & 1,09 & 64,50 & 16,59 & 2,40 & - & - \\
\hline Amande & Congo belge & - & 24,0 & 44,3 & - & 17 & - & '- & - \\
\hline - & 一 & - & 25,5 & $43,7 \bar{i}$ & - & 18,52 & - & - & - \\
\hline - & - & - & 27,6 & 41,5 & - & 23,75 & - & - & 一 \\
\hline - & - & - & 23,3 & 36,5 & - & 20,5 & - & - & - \\
\hline - & Ouganda & 5,95 & 22,87 & 49,19 & 2,60 & 8,41 & 2,95 & 0,09 & 1,02 \\
\hline- & Rhodésie Sud & 8,15 & 27,94 & 43,57 & 2,56 & 15,05 & 2,73 & - & - \\
\hline - & Afrique Sud & 4,8 & 30,3 & 47,3 & 4,0 & 11,5 & 2,1 & 0,19 & 1,01 \\
\hline
\end{tabular}

Les extrêmes observés sur dix analyses d'amandes sont les suivants :

Protéine $\ldots \ldots \ldots \ldots \ldots \ldots . \ldots 24,0$ à 30,3

Extrait éthéré ........... 36,5 à 47,3

Cellulose ............... 2,6 à 4,0

Extr. non azoté $\ldots \ldots \ldots \ldots, 11,5$ à 24

L'arachide est aussi distribuée sous forme de de farine obtenue avec la graine entière. Comme source de protéine, cette farine aurait une valeur moindre que celle de soja ou de graine de coton. Voici la composition d'une farine de Nigeria :

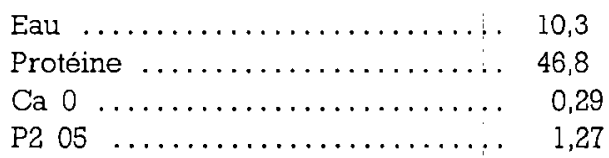

La valeur biologique des protéines de cette 
farine et de la luzerne est respectivement de 56,5 et 54,9 p. 100 , la digestibilité de 93 et 83,5 p. 100 .

Le beurre d'arachide n'est guère utilisé qu'en alimentation humaine, particulièrement aux U.S.A. On l'obtient en broyant des arachides grillées. Il renferme 51 p. 100 de matières grasses, 27,8 p. 100 de matières azotées et 13,2 p. 100 d'hydrates de carbone.

Le « lait d'arachide » est préparé de la façon suivante : on broie la graine avec de l'eau pour en faire une pâte qu'on reprend ensuite avec de l'eau, à l'ébullition. On fait aussi le lait avec la graine germée pendant deux jours à $25^{\circ}-30^{\circ}$; on enlève ensuite l'enveloppe et on chauffe à $80^{\circ}$ pendant 10 minutes avec 0,1 p. 100 de bicarbonate de soude, on lave et on écrase en pâte fine qu'on mélange par agitation à de l'eau en quantité suffisante; on fait ensuite bouillir 15 minutes. Ce « lait » contient des protéines plus digestibles que les protéines de la graine, mais inférieures à celle du lait de vache; 1 l est plus riche que ce dernier en acide nicotinique et en vitamine Bl.

Les sous-produits du traitement industriel de la graine sont divers. Le décorticage la débarrasse du péricarpe et de l'épisperme. La coque ¡présente, à l'intérieur, une pellicule noirâtre qui fournit les sons gras. La graine laisse une pellicule rouge qui donne le son d'arachide proprement dit.L'amande traitée par pression ou par les solvants laisse les tourteaux, dont certains, délipidés sont dits grumeaux.

Les coques sont de faible valeur alimentaire. Nous avons donné plus haut l'analyse de produits de Rhodésie. Les coques du Sénégal renferment en moyenne 10 à 12 p. 100 d'eau, 3,80 à 4,8 p. 100 de matières azotées, 50 à 55 p. 100 de cellulose brute, 8 à 13 p. 100 de cellulose saccharifiable, 1,4 à 3,6 p. 100 de cendres. La teneur en matière azotée est inférieure à celle du foin. Aussi sont-elles utilisées comme combustibles, comme litière, comme engrais beaucoup plus que comme aliment. Dans ce cas, elles ne servent guère que comme support d'un aliment riche. On en fait parfois une poudre qualifiée frauduleusement son d'arachide.

Le son proprement dit a une composition voisine de celle des coques: La teneur en matière azotée est en moyemne de 2,5 p. 100. Aussi les emploie-t-on peu comme aliments. Ils renferment d'ailieurs un principe astringent gênant. Souvent, on les incorpore aux tourteaux.

Les " sons gras" ont une composition variable, en raison des proportions diverses des éléments qui y entrent : outre la pellicule qui en représente la plus grande partie, il y a des germes, des fragments d'amandes, des débris de pellicule rouge, parfois de coques.

De façon générale, ces sons sont riches en matière grasse 10 à 20 p. 100, en protéine, 15 à 20. La teneur en matière grasse gêne la conservation.

Le tourteau varie en composition : tourteau décortiqué ou non, tourteau obtenu par pression ou par solvants, tourteaux plus ou moins colorés (tourteaux « Rufisque » blancs, tourteaux « Coromandel» bruns).

La composition moyenne d'un bon tourteau est la suivante :

\begin{tabular}{rccccccc} 
& Eau & Protéine & Graisse & H. de C. & \multicolumn{2}{c}{ Cellulose Cendres } \\
Non décortiqué & 10 & 30 & 9 & 22 & 23 & 6 \\
décortiqué & 10 & 47 & 7 & 24 & 6 & 6
\end{tabular}

Les tourteaux indigènes surtout subissent des variations importantes en ce qui concerne la matière grasse. C'est ainsi que, sur huit échantillons de Tanganyika, on note les differences suivantes :

\begin{tabular}{|c|c|c|}
\hline Protéine $\ldots$. & 43,33 & à 53,1 \\
\hline Extrait éthéré & 4,71 & à 16,2 \\
\hline Cellulose .............. & 4,5 & à 8,70 \\
\hline Ion azoté $\ldots . . \ldots$. & 23,1 & 37,94 \\
\hline Cendres $\ldots . .$. & 4,1 & à 6,66 \\
\hline & 0,235 & 0.5 \\
\hline $\mathrm{P} 2$ & 1,40 & 1,50 \\
\hline
\end{tabular}

Dans les tourteaux industriels par pression, la teneur en graisses tourne autour de 6 à 8 p. 100; dans les tourteaux par solvants, autour de 1 à 3 p. 100 . Dans les deux variétés, la teneur en protéine approché ou dépasse légèrement $50 \mathrm{p}$. 100 . Le tourteau d'arachide est de toute façon le plus riche en protéine (palmiste : 15 p. 100, coprah : 17 p. 100).

Son coefficient d'utilisation très élevé ( $98 \mathrm{p} .100$ ) est plus grand que celui de tous les grains. Il faut tenir compte de la détérioration des protéines qu'entraîne la conservation prolongée.

Sur des tourteaux obtenus en France par pression ou extraction on note les différences suivantes :

\begin{tabular}{|c|c|c|}
\hline Matière sèche & $\begin{array}{l}\text { Pression } \\
90\end{array}$ & $\begin{array}{c}\text { Extraction } \\
89\end{array}$ \\
\hline Protéine $\ldots \ldots \ldots \ldots \ldots \ldots$ & 43 & 47 \\
\hline Extrait éthéré $\ldots \ldots \ldots \ldots \ldots$ & 8 & 2,5 \\
\hline Cellulose.............. & 7 & 6 \\
\hline Extr, non azoté $\ldots \ldots \ldots \ldots$ & 27 & 29 \\
\hline $\mathrm{Ca} \% \ldots \ldots \ldots \ldots \ldots \ldots$ & 1,5 & 1,7 \\
\hline$P \%{ }^{\circ} \ldots$ & 5,5 & 5,7 \\
\hline
\end{tabular}

Le tourteau par pression renferme :

Vit. $\AA(\mathrm{U} .1 / \mathrm{kg}) \ldots \ldots \ldots \ldots \ldots \ldots \ldots . \ldots 40$

Vit. Bl $(\gamma / \mathrm{kg}) \ldots \ldots \ldots \ldots \ldots \ldots \ldots .4400$

Vit. B2 $(\gamma / \mathrm{kg}) \ldots \ldots \ldots \ldots \ldots . \ldots 2000$ 
La teneur en acides aminés comprend 15 de ces constituants, mais elle est insuffisante en ce qui concerne la méthionine et la lysine; le facteur limitant parait être la méthionine. On ne peut par exemple le donner comme seule source de protéine dans une ration pour poussins. La déficience ne peut être comblée par le soja, auquel cas la ration reste inférieure en méthionine, ni par la farine de coton, insuffisante en lysine. Par contre, la teneur en acides aminés, malgré cette déficience. fait que le tourteau d'arachide réussit mieux chez le porc que le tourteau de colza.

On retrouve dans le tourteau les deux globulines de la graine, l'arachine et la conarachine.

Quant aux hydrates de carbone (tourteau décortiqué) ils se répartissent ainsi :

Hydrates de C. saccharifiables ...... 21,1

Cellulose...................... 4

Autres, non saccharifiables ........ 3,6
Les vitamines lipo-solubles varient selon la teneur en matière grasse. La vitamine $C$ n'existe pas dans les tourteaux par solvants. Dans les tourteaux délipidés, il y aurait (Morrison) $0,176 \mathrm{mg} / \mathrm{kg}$ de carotène.

Quant aux vitamines hydro-solubles, la teneur est la suivante (Morrison) en $\mathrm{mg} / \mathrm{kg}$ : Vitamine $\mathrm{Bl}$ : 7,2; Vitamine B2 : 2,3; vitamine PP: 170,5 ; acide pantothénique : $5,3:$ choline $: 1,850$.

\section{Genre Bauhinia}

Comme nous l'avons dit : le rôle' fourrager des espèces du genre est dû pour bonne part aux gousses, Nous indiquons ci-dessous des analyses s'ajoutant à celles que nous avons citées

\begin{tabular}{|c|c|c|c|c|c|c|c|c|c|}
\hline Produits & Origine & Eau & Protéine & $\begin{array}{c}\text { Ex- } \\
\text { trait } \\
\text { ethé- } \\
\text { ré- }\end{array}$ & $\begin{array}{l}\text { Cellu- } \\
\text { lose }\end{array}$ & $\mid \begin{array}{c}\text { Extracti } \\
\text { non } \\
\text { azoté }\end{array}$ & $\begin{array}{l}! \\
\text { Cen- } \\
\text { dres }\end{array}$ & $\mathrm{CaO}$ & P2 05 \\
\hline B. esculenta amande $\ldots \ldots \ldots \ldots \ldots$ & Queensland & - & 34,2 & 43,3 & 1,4 & 17,9 & 3,2 & - & - \\
\hline enveloppes ... & - & - & 2,7 & 0,2 & 21,6 & 73,4 & 2,0 & - & - \\
\hline graine entière.... & - & - & 19,2 & 22,7 & 11,1 & 44,3 & 2,7 & - & - \\
\hline B. reticulata gousses . & Nigeria & 9,8 & 7,0 & 2,0 & 26,2 & 60,5 & 4,3 & 0,40 & 0,14 \\
\hline B. thonningii gousses.. & Rhodésie Nord & 5,0 & 6,9 & 2,2 & 22,5 & 58,9 & 5,5 & - & - \\
\hline B. thonninghii gousses . & Rhodésie Sud & 6,1 & 6,6 & 3,1 & 23,7 & 56,6 & 3,9 & - & - \\
\hline
\end{tabular}

\section{Genre Bradburya}

Les graines de plusieurs espèces fourragères du genre sont mangées en Amérique du Sud.

\section{Genre Cajanus}

Le pois d'Angola, Cajanus indicus, outre son feuillage, donne d'excellentes graines qu'on donne surtout aux porcs et aux chevaux. Les moutons les mangent également et la farine peut être incorporée à la ration des volailles.

Voici la composition de divers échantillons.

Soudan Sierra Leone Nigeria Gold Coast

\begin{tabular}{lrrrr} 
Eau .......... & 7,49 & 9,1 & 11,72 & \multicolumn{1}{c}{-} \\
Protéine ....... & 20,11 & 18,1 & 18,60 & 20,45 \\
Extrait éthéré . & 1,66 & 1,0 & 1,42 & 2,56 \\
Cellulose ..... & 6,26 & 6,4 & 8,06 & 7,14 \\
Extr. non azoté & 60,58 & 61,8 & 57,12 & 65,69 \\
Cendres ...... & 3,95 & 3,6 & 3,28 & 4,16 \\
Ca $0 \ldots \ldots . . .$. & - & - & - & 0,29 \\
P2 05 ........ & - & - & - & 0,84
\end{tabular}

\section{Genre Canavalla}

Nous avons vu l'intérêt fourrager du pois sabre, Canavalia ensiformis. Outre le feuillage, les graines vont à l'alimentation humaine ou animale', selon les régions.

Dans l'Inde, on les considère comme de médiocre qualité. A Maurice, la culture s'est étendue pour distribution aux animaux (bovins) de la graine concassée et bouillie. Elle peut en effet, non bouillie, causer des accidents dus à l'acide cyanhydrique. Nous l'avons observé au Soudan.

A Hawaï, on utilise pour les vaches laitières avec d'excellents résultats, un mélange de graines vertes de Canavalia avec du sorgho en égale proportion.

Quand on nourrit des rats avec de la farine de Canavalia ensiformis, ils meurent assez rapidement avec des lésions de gastrite hémorragique, avec ulcérations; la toxicité ne se révèle pas quand on ne donne qu'un dixième à un tiers du produit mêlé à 
de la farine de céréales. Le produit toxique semble exister dans l'endosperme, il est thermolabile.

La composition subit quelques variations. Des graines du Soudan domnent :

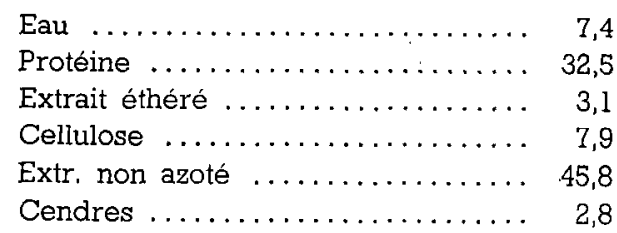

Deux échantillons de Gold Coast renferment

\begin{tabular}{|c|c|}
\hline & 8,2 et \\
\hline Protéine ..... & 27,4 et 31,62 \\
\hline Extrait éthéré & 1,3 et 3,15 \\
\hline Cellulose....... & 14,7 et 8,12 \\
\hline Extr. non azoté . & 45,7 et 53,97 \\
\hline Cendres...$\ldots \ldots$ & 2,7 et 3,14 \\
\hline
\end{tabular}

Les différences de composition entre l'enveloppe et la graine décortiquées (Gold Coast) sont les suivanles

\begin{tabular}{|c|c|c|}
\hline & Enveloppe & Graine décortiquée \\
\hline Protéine. & 4,52 & 38,24 \\
\hline Extrait éthéré ..... & 1,48 & 3,10 \\
\hline Cellulose $\ldots \ldots \ldots$. & 48,10 & 1,10 \\
\hline Extr. non azoté & 42,14 & 54,50 \\
\hline Cendres ...... & 3,76 & 3,06 \\
\hline
\end{tabular}

Canavalia obtusifolia est une espèce voisine de C. ensiformis. Les graines sont également données aux animaux et peuvent causer des accidents d'origine cyanogénétique. Leur composition est la suivante (Gold Coast) :

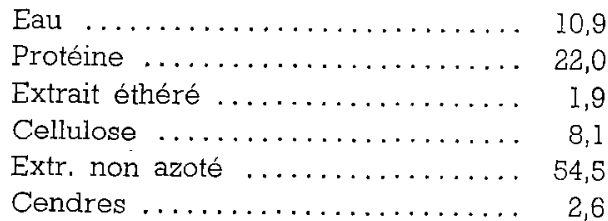

\section{Cenre Cassia}

Nous avons indiqué les espèces dont les fruits, à côté des feuilles, sont mangées et le danger que présentent les graines de certaines espèces. Voici la composition d'une graine de Cassia (C. nictitans).

\begin{tabular}{|c|c|}
\hline Protéine & 40,0 \\
\hline Extrait éthéré .. & 3,0 \\
\hline Cellulose ....... & 7,7 \\
\hline Extr. non azoté... & 45,0 \\
\hline Cendres ........ & 4,7 \\
\hline $\mathrm{Ca}, \mathrm{O} \ldots \ldots \ldots \ldots \ldots \ldots$ & 0,51 \\
\hline P2 $05 \quad \ldots \ldots \ldots \ldots \ldots \ldots \ldots \ldots$ & 0,55 \\
\hline
\end{tabular}

\section{Genre Ceratonia}

Le caroubier, Ceratonia siliqua, grand arbre de l'Afrique du Nord qui a été introduit en diverses régions chaudes, produit des gousses qui sont depuis longtemps utilisées dans l'alimentation humaine et animale. On utilise les gousses entières, avec les graines, ou encore les gousses sans les graines, ou plus rarement celles-ci seules. Le traitement industriel des gousses fournit en outre divers sous-produits.

La composition des caroubes entières subit des variations marquées selon les variétés, les régions, la saison, le stade de maturité. Dans la région méditerranéenne, on remarque les différences suivantes :

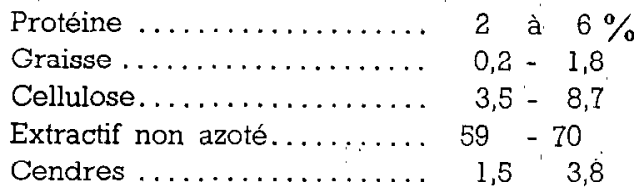

En Afrique du Sud, une analyse donne

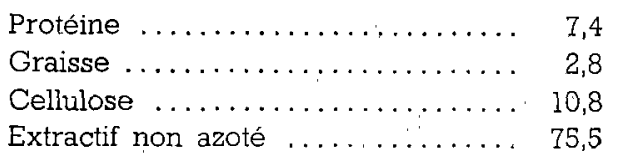

Une moyenne établie sur. des chiffres obtenus, avec des produits d'Australie, d'Amérique du Nord et du Sud, de Rhodésie, de Palestine, donne :

\begin{tabular}{|c|c|}
\hline Protéine ..... & 5,8 \\
\hline Extrait éthéré $\ldots \ldots \ldots \ldots \ldots \ldots$ & 1,2 \\
\hline Cellulose brute $\ldots \ldots \ldots \ldots \ldots \ldots$ & \\
\hline Extractif non azoté $\ldots \ldots \ldots \ldots \ldots$ & 81,7 \\
\hline Cendres $\ldots \ldots \ldots \ldots \ldots \ldots \ldots$ & 2,9 \\
\hline$\ldots \ldots \ldots \ldots \ldots \ldots \ldots$ & \\
\hline
\end{tabular}

La composition comparée des gousses et des graines, pour des variétés d'Afrique du Nord, donne :

\begin{tabular}{|c|c|c|c|}
\hline & Graines & Cousses & usses avec Graines \\
\hline Eau & & 11,50 & ]3,28 \\
\hline Protéine. & 16,46 & 4,50 & 6,75 \\
\hline Graisses & 2,50 & 2,37 & 2,17 \\
\hline Sucre réductible & »: & 11,24 & 11,08 \\
\hline Sucrose $\ldots \ldots \ldots \ldots$ & $»$ & 23,17 & 19,44 \\
\hline Matières amylacées & 58,61 & 36,30 & 39,80 \\
\hline Cellulose...$\ldots \ldots$. & 7,50 & 8,78 & 9,29 \\
\hline Cendres. & 3,18 & 2,72 & 2,57 \\
\hline
\end{tabular}

Avec des produits de Rhodésie et de Palestine :

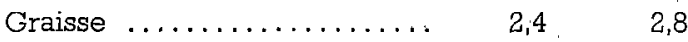

Cellulose ............... $\quad 10,2 \quad 8,6$

Extractif non azoté ......... $80,7 \quad 66,7$

Cendres $\ldots \ldots \ldots \ldots \ldots \ldots \ldots . \quad 2,8 \quad 3,6$ 
D'autres analyses donnent des chiffres très voisins (p. 100 sur la matière sèche) en ce qui concerne les graines :

\begin{tabular}{|c|c|}
\hline Protéine brute ... & 18,5 \\
\hline Extrait éthéré $\ldots . .$. & 2,0 \\
\hline Cellulose brute ..... & 8,0 \\
\hline Extractif non azoté ... & 68,0 \\
\hline Cendres .......... & \\
\hline
\end{tabular}

Après traitement industriel des caroubes, notamment pour obtenir un apprêt utilisé dans l'industrie textile, on peut recueillir le germe, lequel comprend l'embryon et les cotylédons. C'est un aliment concentré de grande valeur nutritive malgré sa faible teneur en Ca. "La composition de deux échantillons est la suivante :

\begin{tabular}{|c|c|}
\hline Eau & 9,6 et 11,6 \\
\hline Protéine brute.......... & 40,49 et 45,1 \\
\hline Extrait éthéré $\ldots \ldots \ldots \ldots \ldots$ & 3,50 et 5,2 \\
\hline Extractif non azoté........ & 33,18 et 40,2 \\
\hline Cellulose brute .... & 8,05 et \\
\hline Cendres ......... & 5,58 et \\
\hline
\end{tabular}

Les cendres renferment 7,33 p. 100 de Ca et 16,3 p. 100 de P. La teneur en vitamines est assez faible.

D'autres analyses donnent 25 p. 100 de matière azotée digestible.

La pulpe résiduelle après obtention de l'alcool de caroubes a la valeur, du point de vue de la composition, d'un foin de bonne qualité, mais sa digestibilité est très faible. Elle contient, pour 100 de matière sèche (la teneur en eau etant de 17 p. 100).

$\begin{array}{lrr}\text { Protéine brute } \ldots \ldots \ldots \ldots \ldots \ldots \ldots \ldots & 10,40 \\ \text { Extrait éthéré } \ldots \ldots \ldots \ldots \ldots \ldots \ldots \ldots \ldots & 0,71 \\ \text { Cellulose brute } \ldots \ldots \ldots \ldots \ldots \ldots \ldots \ldots & 18,15 \\ \text { Extractif non azote } \ldots \ldots \ldots \ldots \ldots \ldots \ldots & 65,80 \\ \text { Cendres } \ldots \ldots \ldots \ldots \ldots \ldots \ldots \ldots \ldots \ldots . & 4,94\end{array}$

La farine de germes est riche en acides aminés, plus riche que le gluten de blé, surtout en lysine, acide aspartique et arginine, un peu plus en histidine et glucine, moins en cystine, beaucoup moins en proline.

L'intérêt présenté par les caroubes a d'abord suscité des essais d'introduction de l'arbre en de nombreuses régions subtropicales; Ceratonia siliqua $\mathrm{y}$ était considéré à la fois comme un arbre fourrager et un arbre d'ornement et d'ombrage : Nouvelle Zélande, Nouvelles Galles du Sud, Australie de l'Ouest, Amérique du Nord et du Sud, Palestine. Le succès a été relatif, et encore moins marqué dans des régions plus chaudes (Ouganda). Les essais réalisés du temps de Faidherbe au Sénégal ont été infructueux comme ceux qui furent tentés beau- coup plus tard au Soudan. Aussi le caroubier, greffé ou non, n'a-t-il pas pris d'extension en dehors de l'Afrique du Nord, mises à part quelques régions en Australie, et dans le Sud des Etats-Unis, en régions semi-arides où le froid n'est pas trop fort. Un gros obstacle est la lenteur de la pousse; on sème les graines; l'année suivante, on met, en pépinière et on transplante un an après, en bordures ou en massifs. Il faut 15 à 20 ans pour avoir de bonnes récoltes.

On distribue aux anirnaux sous des formes varièes; les graines dures, si on les donne seules, ne sont pas mastiquées par les animaux et traversent intactes le tube digestif. Aussi les donne-t-on sous forme de farine. On fait aussi une farine avec le fruit entier, gousse et graines. Cette farine, qui contient environ 5,5 p. 100 de protéine et 9 a 10 p. 100 de cellulose. peut remplacer le maïs dans la ration. Il a été cependant remarqué que cette substitution chez le poulet, abaisse le taux de croissance de 15 à 50 p. 100.

Les gousses, privées des graines, riches en sucre et pauvres en protéine, sont bien appétées par les bovins, les chevaux. Elles peuvent remplacer, chez les vaches, environ moitié du grain, concassées ou en poudre. Leur altération est facile et peut causer des accidents.

\section{|Genre Cercidium}

Les pousses et les fruits de plusieurs Cercidium, notamment $C$. peninsulare, sont mangés par le bétail et ont la réputation de pousser à l'engraissement.

\section{Cenre Cicer}

Le poids chiche, graine de Cicer arietinum, est utilisé dans l'alimentation animale, surtout dans l'Inde (horse-gram) où on lui attribue l'avantage de ne pas causer chez le cheval d'échauffement ou d'excitation. On l'utilise aussi chez les vaches et les volailles, de préférence après concassage. On l'emploie aussi en Afrique du Nord, en Afrique orientale, etc.

Dans l'Inde où c'est la graine la plus employée pour les diverses espèces animales, Lander la considère comme un aliment surtout azoté en raison de sa teneur en protéine, qui avoisine 20 p. 100. La teneur en calcium est de 0.7 p. 100, en phosphore de 0,6 p. 100.

On donne jusqu'à 3-4 livres par jour aux chevaux, la même quantité aux boeufs et buffles. Aux vaches de 800 livres, on peut donner 2,5 à 3 livres. 
Deux analyses (Nyasaland et Somalie) donnent les résultats suivants :
Eau .................
8,78 et 9,58
Protéine 22,80 et 16,95

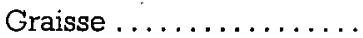
4,87 et 5,25
Cellulose...............
3,54 et 8,32
Extractif nón azoté...... 57,12 et 56,13
Cendres ........... 2,89 et 3,77

La protéine est incomplète et sa valeur biologique est environ égale à la moitié de celle de la caséine.

La teneur en protéines varie avec les variétés et l'année de récolte. Des graines récoltées la même année ont une teneur en azote total qui varie de 2,95 à 3,44 p. 100 avec la variété. Le soufre total et le pourcentage de méthionine varient peu avec les variétés, mais il y a de grosses différences dans le soufre total et les acides aminés soufrés selon l'année de récolte. Alors qu'il y a de grandes différences selon les variétés dans la teneur en lysine, elles sont insignifiantes en ce qui concerne l'arginine et l'histidine.

\section{Genre Cyamopsis}

Ainsi que nous l'avons indiqué, plusieurs espèces du genre constituent de bons fourrages. Les graines sont également intéressantes. C'est particulièrement le cas de celle de C. psoraloïdes, qui est utilisée dans l'Inde comme substitut de celle de Cicer arietinum chez tous les animaux sauf le cheval. Elle contient environ deux fois plus de protéine que le pois chiche (40 p. 100); elle est riche en phosphore, pauvre en calcium $(\mathrm{Ca}=0 ; 4 \mathrm{p} .100$; $P: 1,3$ p. 100). On la distribue à tous les animaux, sauf au cheval, à des doses moitié de celles du pois chiche.

Les graines de C. psoraloides et $C$. tetragonolobus sont utilisées par l'industrie pour l'obtention de colles. Le résidu, dénommé " guvitrine " renferme $14 \mathrm{p} .100$ d'eau et sur la matière sèche :

Protéine .............. 55,5

Cellulose .............. 8,5

Extractif non azote $\ldots \ldots \ldots \ldots 30,6$

Cendres................. 5,4

Graisses.................. traces

on en distribue $1 \mathrm{~kg}$ à $1,500 \mathrm{~kg}$. par jour aux bovins.

\section{Genre Dichrostachys}

Les arbres africains de ce genre ont, nous l'avons $\mathrm{vu}$, des gousses que recherchent les animaux, Leur composition est la suivante

\begin{tabular}{|c|c|c|c|c|c|c|c|c|c|}
\hline Produit & Origine & Eau & Protéine & $\begin{array}{l}\text { Ex- } \\
\text { trait } \\
\text { ethé- } \\
\text { ré }\end{array}$ & $\begin{array}{l}\text { Cell11- } \\
\text { lose }\end{array}$ & $\begin{array}{c}\text { Extractif } \\
\text { non } \\
\text { azoté }\end{array}$ & $\begin{array}{l}\text { Cen- } \\
\text { dres }\end{array}$ & $\mathrm{Ca}$ & $\mathrm{r}^{\prime}$ \\
\hline D. glomerata gousses & Nigeria & - & 11,4 & 1,2 & 25,6 & 56,4 & 5,5 & $0 ; 51$ & 0,20 \\
\hline graines. . & - & - & 20 & 2,2 & 21,8 & 51,5 & 4,9 & - & - \\
\hline gousses & Tanganyika & - & 10,82 & 1,42 & 26,64 & 55,76 & 5,66 & 0,71 & 0,45 \\
\hline D. nutans graines & Rhodésie & 7,08 & 18,55 & 2,07 & 20,27 & 47,64 & 4,54 & - & - \\
\hline fruits.. & Nigeria & 9,9 & 10,7 & 0,8 & 22,2 & 51,38 & 5,02 & - & - \\
\hline
\end{tabular}

\section{Genre Dolichos}

Nous avons vu les qualités de divers Dolichos comme fourrages. Les graines sont aussi utilisées.

Dolichos lablab est cultivé accessoirement pour la graine. Dans l'Inde on utilise couramment celle de $D$. biflorus, qui serait plus économique que les autres, et que l'avoine; c'est le' « horse gram », nom qui est d'ailleurs appliqué à divers " haricots» et notamment à $D$. uniflorus (variété de biflorus) et à $D$. multiflorus et aussi au pois chiche.
La composition de deux échantillons de D. lablab est la suivante

\begin{tabular}{|c|c|c|}
\hline & Rhodèsie & Soudan \\
\hline Eau $\ldots \ldots \ldots \ldots \ldots \ldots \ldots$. & 8,03 & 7,40 \\
\hline Protéine. & 24,72 & 23,53 \\
\hline Extrait éthéré $\ldots \ldots \ldots \ldots$ & 1,0 & 1,05 \\
\hline Cellulose . . & 9,77 & $7 ; 95$ \\
\hline 'xtractif non azoté & 52,58 & 56,28 \\
\hline endres & 3,90 & 3,7 \\
\hline
\end{tabular}




\section{Genre Ervum}

La lentille bâtarde, Ervum ervilia, est cultivée comme fourrage en Afrique du Nord. Les accidents qui auraient été constatés après consommation prolongée viennent de la graine et se rattachent à ceux que causent les gesses. Les graines renferment en moyenne :

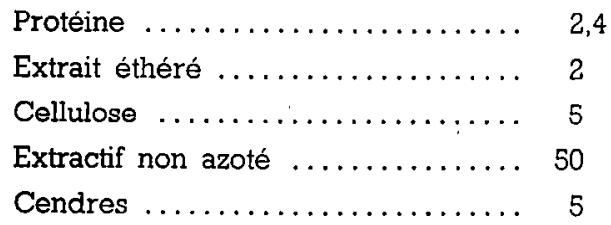

\section{Genre Gleditschia}

Nous avons indiqué précédemment l'essentiel concernant les fruits de l'arbre à miel, Gleditschia triacanthos.

(Voir Soja).

\section{Genre Glycine}

\section{Genre Indigofera}

Parmi les espèces du genre utilisées comme engrais vert, plantes de couverture, parfois fourrage, il en est dont les graines pourraient être données aux animaux. C'est le cas de celles d'Indigofera glandulosa, de l'Inde, qui contiennent

$\begin{array}{ll}\text { Eau } \ldots \ldots \ldots \ldots \ldots \ldots \ldots \ldots \ldots \ldots & 9,3 \\ \text { Protéine } \ldots \ldots \ldots \ldots \ldots \ldots \ldots \ldots \ldots & 31,7 \\ \text { Extrait éthéré } \ldots \ldots \ldots \ldots \ldots \ldots \ldots \ldots & 4 \\ \text { Cellulose } \ldots \ldots \ldots \ldots \ldots \ldots \ldots \ldots & 8,1 \\ \text { Extractif non azoté } \ldots \ldots \ldots \ldots \ldots \ldots & 43,4 \\ \text { Cendres } \ldots \ldots \ldots \ldots \ldots \ldots \ldots \ldots & 3,5\end{array}$

\section{Genre Lathyrus}

Les " gesses 》 qui, en régions sub-tropicales, sont utilisées comme fourrage, plantes de couverture, sont rarement cultivees pour leurs graines : Lathyrus sativus, $L$. tingitanus, $L$. cicera. On sait le danger que présente une alimentation prolongée. La composition est :

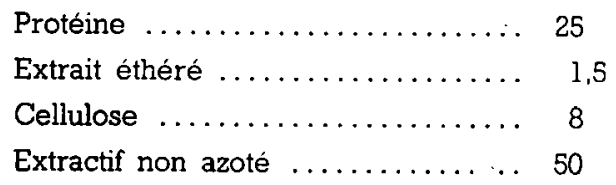

\section{Genre Lespedeza}

Dans l'Inde, en Amérique où les espèces comme $L$. sericea sont de plus en plus utilisées comme fourrage, les graines renferment :

\begin{tabular}{|c|c|c|}
\hline & \multicolumn{2}{|c|}{ Décortiquées Non décortiquées } \\
\hline Protéine $\ldots \ldots \ldots \ldots \ldots \ldots$ & 38,2 & 32,3 \\
\hline Extrait éthéré $\ldots \ldots \ldots$ & 4,5 & 4,6 \\
\hline Cellulose .............. & 13,6 & 16.7 \\
\hline Extractif non azoté ...... & 40,8 & 42,7 \\
\hline Cendres $\ldots \ldots \ldots \ldots \ldots$ & 3,9 & 4,3 \\
\hline $\mathrm{Ca} \ldots \ldots \ldots \ldots \ldots \ldots$ & 0,14 & 0,58 \\
\hline 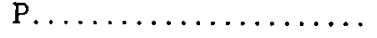 & 0,54 & 0,50 \\
\hline
\end{tabular}

\section{Genre Leucaena}

Nous avons indiqué la composition de divers éléments de Leucaena glauca. Voici d'autres chiffres concernant les gousses (Rhodésie du Sud) :

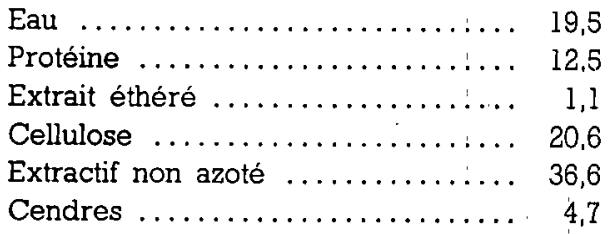

Voici d'autres chiffres concernant la graine, la farine et le son :

\begin{tabular}{|c|c|c|c|}
\hline & Graine & Farine & Son \\
\hline & 29,64 & & \\
\hline heré & 4,84 & 7,02 & 3,20 \\
\hline 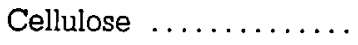 & 14 & 7,80 & 13,90 \\
\hline endres & 3,69 & 4,78 & 3,42 \\
\hline
\end{tabular}

\section{Genre Lupinus}

Nous avons indiqué les espèces du genre qui, en régions tropicales et surtout subtropicales, peuvent être utilisées comme fourrage ou comme plantes améliorantes. Les graines de la plupart d'entre elles sont comestibles, mais souvent dangereuses en raison de la présence d'un alcaloïde ; plusieurs espèces d'Amérique ont causé des accidents, ainsi que des espèces africaines. Il faut donc être circonspect en ce qui concerne leur emploi; à remarquer que la macération fait diparaitres le danger.

La composition se rapproche de celle d'autres graines de Légumineuses. Voici celle d'un' Lupin. d'Afrique orientale :

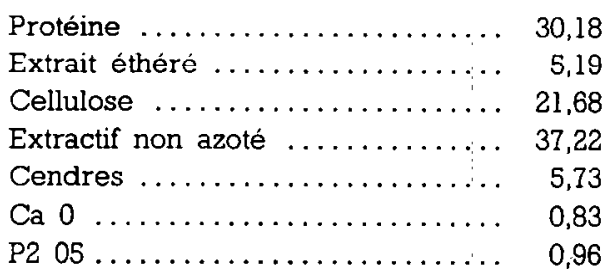


La teneur en matière grasse est variable, puisque l'amande de $L$. ternus, que les habitants mangent au Soudan égyptien, en renferme 3,5 p. 100.

Les graines d'un Lupin de Californie, $L$. albifrons, renferment

Protéine 46,7
Cellulose ............... 16,1

Cendres ................. 4,5

$\mathrm{Ca} 0 \ldots \ldots \ldots \ldots \ldots \ldots \ldots \ldots \ldots \ldots \ldots \ldots \ldots$

P2 $C 5 \ldots \ldots \ldots \ldots \ldots \ldots \ldots \ldots \ldots . \ldots . \ldots 1$

Voici par ailleurs, des analyses diverses de lupins d'Europe méridionale et d'Afrique du Nord :

\begin{tabular}{|c|c|c|c|c|c|}
\hline Produit & $\begin{array}{l}\text { Matière } \\
\text { sèche }\end{array}$ & Protéine & $\begin{array}{l}\text { Extrait } \\
\text { éthéré }\end{array}$ & Cellulose & $\begin{array}{c}\text { Extractif } \\
\text { non azoté }\end{array}$ \\
\hline Lupin jaune................... & 86 & 38,3 & 4,4 & 14,1 & 25,4 \\
\hline Lupin bleu $\ldots \ldots \ldots \ldots$ & 86 & 21,5 & 6,2 & 11,2 & 36,2 \\
\hline Lupin blanc.... & 86 & 29,4 & 7,2 & 12,2 & 34,2 \\
\hline Lupin jaune détoxiqué frais...... & 67,5 & 31,7 & 4,3 & 16 & 14,4 \\
\hline Lupin jaune détoxiqué sec .. & 86 & 40,4 & 3,7 & 20,1 & 18,7 \\
\hline Lupin bleu détoxiqué frais & 67 & 23,5 & 4,3 & 9,5 & 28,6 \\
\hline Lupin bleu détoxiqué sec . & 86 & 30,1 & 5,5 & 12,2 & 36,8 \\
\hline
\end{tabular}

\section{Genres Mucuna et Stizolobium}

Ces deux genres, très voisins, renferment, nous l'avons $\mathrm{vu}$, diverses espèces fourragères. Les graines de certaines peuvent être distribuées aux animaux, sous réserve que, parfois, elles sont cyanogénétiques, ce qui oblige à les faire cuire (St deringianum, St pachypodium).

La graine de Mucuna utilis (= $M$. atropurpurea), le pois noir qu'on cultive à la fois comme plante fourragère et comme plante de couverture, a un pouvoir nutritif très resserré, et doit être donnée en mélange avec des substances moins riches.

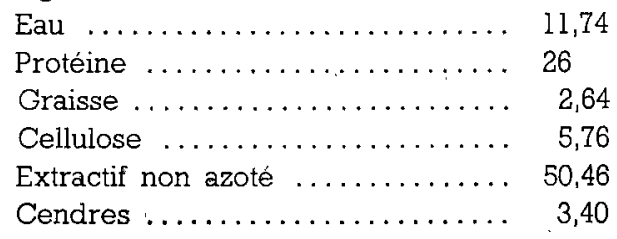

La composition varie selon les variétés; il est aussi de notables différences entre les graincs entières ou décortiquées, etc.

\begin{tabular}{|c|c|c|c|c|c|c|c|c|c|}
\hline Produit & Origine & Eau & Protéine & $\begin{array}{c}\text { Ex- } \\
\text { trait } \\
\text { ethé- } \\
\text { ré }\end{array}$ & $\begin{array}{l}\text { Cellu- } \\
\text { lose }\end{array}$ & $\begin{array}{c}\text { Extracti } \\
\text { non } \\
\text { azoté }\end{array}$ & $\begin{array}{l}\text { Cen- } \\
\text { dres }\end{array}$ & $\mathrm{Ca} 0$ & P2 05 \\
\hline Diverses variétés & Rhodésie Sud & 9,4 & 27,6 & 4,8 & 5,9 & 49,3 & 3,0 & - & - \\
\hline Mucuna sp ....... & Afrique occ. & 一 & 29,10 & 3,31 & 8,35 & 55,91 & 3,33 & 0,18 & 0,99 \\
\hline Variété noire. & Nyasaland & 9,56 & 25,85 . & 3,68 & 7,28 & 50,64 & 2,99 & - & - \\
\hline Variété Somerset. & Rhodésie Sud & 11,0 & 22,9 & 5,1 & 5,7 & 52,2 & 3,1 & - & - \\
\hline Variété blanche $\ldots \ldots \ldots \ldots \ldots$ & Nyasaland & 9,70 & 25,13 & 3,34 & 7,77 & 50,93 & 3,13 & - & - \\
\hline Gousses et graines.......... & Rhodésie Sud & 10,4 & 13,3 & 3 & 14,3 & 55,6 & 3,4 & - & - \\
\hline Cosses. & Afrique occid. & - & 1,56 & 0,67 & 49,36 & 45,36 & 3,06 & 0,69 & 0,11 \\
\hline Amande. & - & - & 35,75 & 3,70 & 57,71 & 57,71 & 3,51 & 0,08 & 1,26 \\
\hline
\end{tabular}

\section{Genre Ornithopus}

Ornithopus sativus, la " serradelle ", est cultivée dans certaines régions chaudes (Brésil, Chili, Afrique du Nord). La graine est distribuée aux animaux.

Elle renferme :
Matiere seche $\ldots \ldots \ldots \ldots \ldots \ldots \ldots$

Protéine .................. 21,4

Extrait éthéré $\ldots \ldots \ldots \ldots \ldots \ldots$. 7,7

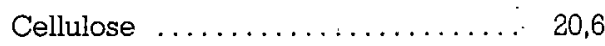

Extractif non azoté ............ 33,2 


\section{Genxe Orobus}

Une espèce voisine des vesces et des gesses, Orobus sp, dénommée "kersannah 》 en Afrique du Nord, peut être cultivée pour sa graine, qu'on distribue aux bovins (au Maroc).

\section{Cenre Parkja}

Un arbre de la forêt - parc de la région soudanaise, Parkia africana (= biglobosa) a des gousses de 30 à $60 \mathrm{~cm}$ qui renferment une pulpe farineuse assez sucrée qui va à l'alimentation humaine. Elle est parfois donnée aux animaux quand elle commencé à s'alterer. Elle fermente en effet assez rapidement en raison de sa teneur en saccharose (plus de $25 \%$ ) et en sucres divers (20 à $22 \%$ ). La graine peut renfermer jusqu'à 25 p. 100 d'huile, pas d'amidon; elle est riche en vitamine B2. Nous avons précédemment indiqué la composition respective de la pulpe et de la graine. Voici des analyses concernant les fruits de Parkia filicoídea de Nigeria, de Gold Coast, du Cameroun, etc. où ils sont mangés par le bétail

\begin{tabular}{|c|c|c|c|c|c|c|}
\hline Produit & Eau & Protéine & $\begin{array}{c}\text { Extrait } \\
\text { éthéré }\end{array}$ & Cellulose & $\begin{array}{c}\text { Extractif } \\
\text { non azoté }\end{array}$ & Cendres \\
\cline { 1 - 4 } Graines .......... & 9,2 & 29,0 & 14,6 & - & 43,2 & 4,0 \\
Graines .......... & 10,1 & 28,5 & 16,8 & 8,3 & 32,4 & 3,9 \\
Pulpe et graines .... & 12,14 & 14,70 & 8,39 & 10,74 & 50,07 & 3,46 \\
Pulpe et graine ..... & 9,35 & 16,0 & 6,14 & 11 & 52,73 & 4,78 \\
Pulpe sans graine ... & 13,1 & 4,2 & 2,0 & 12,6 & 63,5 & 4,0 \\
\hline
\end{tabular}

Les graines renferment 0,75 p. 100 de $\mathrm{Ca} 0$ et 1,07 p. 100 de P2 ( 5 .

\section{Genre Pentaclethra}

Les graines de Pentaclethra macrophylla, de l'Ouest africain renferment

\begin{tabular}{|c|c|c|c|}
\hline & Graine entière & Enveloppe & Amande \\
\hline Protéine.... & . . 24,95 & 7,75 & 24,95 \\
\hline Extrait éthéré & 44,38 & 1,62 & 50,86 \\
\hline Cellulose ....... & 3,63 & 9,94 & 2,70 \\
\hline Extractif non azoté & 24,30 & 75,31 & 19,11 \\
\hline Cendres $\ldots \ldots \ldots \ldots$ & 2,74 & 5,38 & 2,38 \\
\hline $\mathrm{Ca} O \ldots$ & 0,27 & 1,53 & 0,13 \\
\hline P2 O5 & 0,61 & 0,09 & 0,50 \\
\hline
\end{tabular}

Après extraction de l'huile, le tourteau renferme

Protéine ....................... 35

Extrait éthéré .................. 3

Cellulose ..................... 7

Extractif non azoté .............. 42

Cendres ..................... 3

\section{Genre Phaseolus}

Plusieurs espèces de haricots sont cultivées pour leurs graines qui vont à l'alimentation animale.

Phaseolus aconitifolius est une espèce très répandue dans l'Inde, d'où on l'a introduite en diverses autres régions. Elle parait bien réussir au Sénégal, au Texas. Dans l'Inde, on distribue la graine aux chevaux, aux bovins, aux moutons.

La poudre de graines de Phaseolus aconitifolius $i$

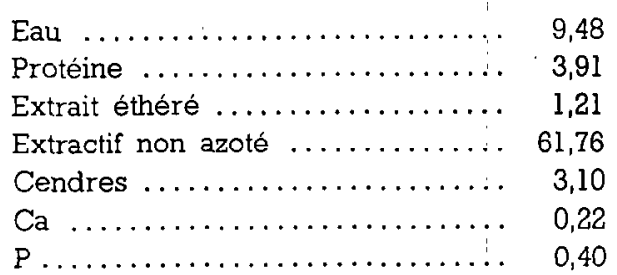

La teneur en acides aminés est de 1 à 2 p. 100, représentés par : lysine, leucine, isoleucine, phenylalanine, tyroxine; il y a peu de cystine et de methionine.

Dans l'Inde, on considère $P$. aconitifolius comme plus riche que le pois chiche. On le donne aux chevaux à raison de 3 livres. Il y a avantage à le concasser en raison de l'épaisseur, ou encore à l'écraser pour donner la poudre aux porcs à l'engrais et aux veaux. Ces produits s'altèrent rapidement.

Phaseolus acutifolius, de l'Inde également, a été introduit en Amérique sub-tropicale, en Afrique du Sud, au Sénégal, surtout comme fourrage vert. Les graines sont également utilisées. Leur composition est la suivante (Afrique du Sud).

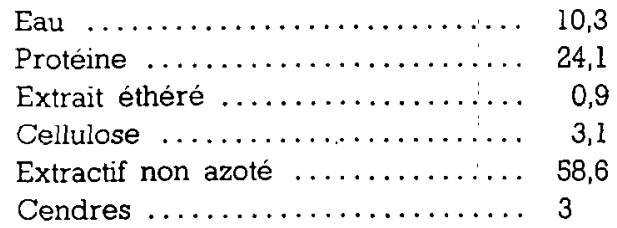

Phaseolus calcaratus, qui croit à l'étai sauvage en Asie et est cultivé en Indochine, conviendrait 
aux régions subtropicales; il a été introduit à Madagascar. En Indochine, on le donne aux chevaux, dans l'Inde également (horse-gram).

Phaseolus lunatus, haricot du Cap, haricot de Madagascar, porte de nombreux noms selon les régions où il est cultivé. On sait que la teneur en acide cyanhydrique change avec les variétés. Bien que réservée habituellement à l'alimentation humaine, a graine est aussi donnée aux animaux. L'analyse de trois échantillons de Sierra Leone donne les résultats suivants :

\begin{tabular}{|c|c|}
\hline Eau & 10,7 à 13,4 \\
\hline Protéine .......... & 20 à 23,4 \\
\hline Extrait éthéré ..... & 0,8 à \\
\hline Cellulose ............ & 3,8 à \\
\hline Extractif non azoté ... & 55,7 à \\
\hline Cendres $\ldots . . .$. & 2,7 \\
\hline
\end{tabular}

P. multiflorus, le haricot d'Espagne est d'origine américaine; il donne de grosses graines réniformes' blanches dans une variété, mais en général roses et tachetées diversement. On le donne rarement aux animaux.

Phaseolus mungo est un haricot cultivé dans I'Inde, aux Antilles, en Egypte, à Madagascar; il y a de nombreuses varićtćs. Co haricot à petite graine est appelé ambérique; il est parfois donné aux animaux.

Diverses variétés de $P$. mungo, souvent traitées comme des espèces, sont intéressantes. C'est le cas de $P$. aureus, de l'Asie tropicale, cultivé comme fourfage en Egypte, en Amérique du Nord.
Phaseolus mungo ( $=P$. radiatus mungo) est facilement cultivable en Cochinchine. Deux échantillons de graines donnent à l'analyse les résultats suivants :

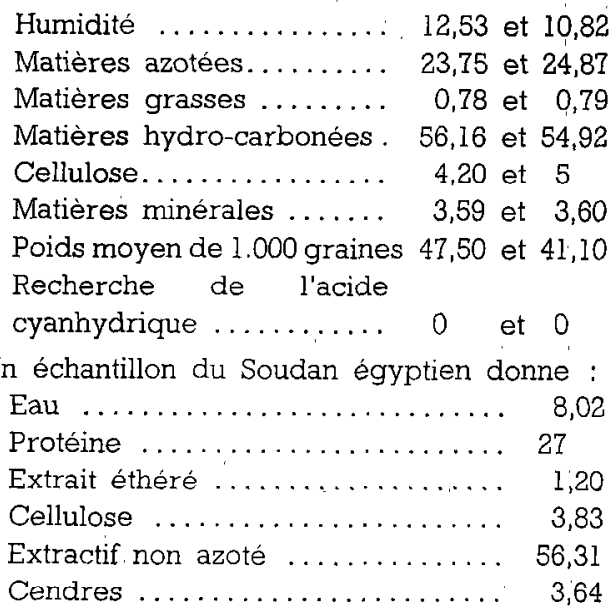

Phaseolus radiatus mungo va surtout, dans l'Inde, à l'alimentation humaine; on le traite, ainsi que d'autres haricots, pour l'obtention d'une farine alimentaire. Le son qui subsiste est utilisé pour le bétail.

\section{Genre Prosopis}

Ainsi que nous l'avons indiqué, ce sont les gousses :des diverses espèces de ce genre qui ont un jntérêt fourrager, plus que les feuilles. Leur composition est la suivante

\begin{tabular}{|c|c|c|c|c|c|c|c|c|c|}
\hline Produit. & Origine & Eau & $\begin{array}{l}\text { Fro- } \\
\text { téine }\end{array}$ & $\begin{array}{l}\text { Extrait } \\
\text { éthéré }\end{array}$ & $\begin{array}{l}\text { Cellu- } \\
\text { Iose }\end{array}$ & $\begin{array}{l}\text { Extrac- } \\
\text { tif non } \\
\text { azoté }\end{array}$ & $\begin{array}{l}\text { Cen- } \\
\text { dres }\end{array}$ & $\mathrm{Ca}$ & $\mathrm{P}$ \\
\hline p. chilensis gouisses ..... & Texas & 10,8 & 13,17 & 1,9 & 27,9 & 52,6 & 3,9 & 0,65 & 0,20 \\
\hline - grainès (farine). & Hawaï & - & 9,5 & 1,5 & 23,2 & 57,9 & 4,3 & - & - \\
\hline goússes $\ldots . . .$. & Soudan & 5,6 & 18,9 & 4,2 & 37,3 & 41,5 & 8,2 & 3,04 & 0,19 \\
\hline P. Júlifiora fruit $\ldots \ldots \ldots$ & Soudan & - & 13,0 & 2,5 & 27,4 & 52,5 & 4,6 & - & - \\
\hline Aruit péricarpe. & - & - & 6,7 & 1,0 & 31,3 & 56,5 & 4,5 & - & - \\
\hline - fruit graine ........... & 一 & - & 36,3 & 4,9 & 7,5 & 47,2 & 4,7 & - & - \\
\hline - enveloppes des graines. & - & - & 4,3 & 0,6 & 54,3 & 37,3 & 3,4 & - & - \\
\hline$-\quad$ amandes $\ldots \ldots \ldots \ldots \ldots$ & $\quad-$ & - & 65,2 & 7,8 & 2,8 & 19,1 & 5,2 & - & - \\
\hline fruit entier .... & Afrique du Sud & - & 13 & 2,5 & 27,4 & 52,5 & 4,6 & -- & - \\
\hline péricarpe ............. & - & - & 6,68 & 10 & 31,3 & 56,51 & 4,5, & - & - \\
\hline - enveloppe des graines. & - & - & 7,70 & 0,65 & 12,04 & 77,34 & 2,07 & $\therefore$ & - \\
\hline P. stephaniana gousses .......... & Arizona & - & 14,5 & 2,9 & 15,17 & 63,2 & 3,8 & - & - \\
\hline - $\quad$ graines...$\ldots \ldots$ & - & - & 20,1 & 3,1 & $9 ; 3$ & 64,1 & 3,4 . & 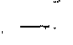 & - \\
\hline P. velutina gousses $\ldots \ldots \ldots \ldots \ldots$ & - & - & 13,9 & 2,9 & 24,4 & 53,9 & 4,9 & - & - \\
\hline - $\quad$ graines ..... & - & $-\dot{-}$ & 37,3 & 6,1 & 6,6 & 46,5 & 3,5 . & - & - \\
\hline Prosopis sp gousses ... & Hàwaï & 11,5 & 10,2 & 0,6 & 25,4 & 60,0 & 3,8 & - & - \\
\hline - graines..... & - & - & 35,2 & 5,2 & 9,1 & 45,4 & 5,1 & - & - \\
\hline Prosopis oblonga fruits... & Nigeria & 9,6 & 9,2 & 3,0 & 21,1 & 53,0 & 3,08 & 0,22 & 0,29 \\
\hline
\end{tabular}




\section{Genre Pterocarpus}

Les diverses espèces du genre, africaines ou asiatiques ont, nous l'avons vu, des feuilles intéressantes. Ce sont surtout les fruits qui sont distribues (notamment en A.O.F.) en raison de leurs caractéristiques, qui ont valu au genre sa dénomination; ce sont de grosses grappes, qu'on utilise, avant maturité surtout; elles sont formées par des fruits à grandes ailes membraneuses tendres renfermant une graine de la grosseur d'un pois qui, à maturité. a une composition voisine de celle du pois d'Angola, avec une proportion moindre de cellulose. Ces fruits sont surtout distribués aux bovins, souvent avec les gousses de Cassia sieberiana.

\section{Genre Soja}

Le soja doit à sa composition spéciale des utilisations nombreuses et variées; longtemps, en dehors de I'Extrême-Orient, il n'a guere été ulilisé, pour l'alimentation humaine et était surtout destiné aux animaux et à l'industrie.

Vont à l'alimentation : la grairie, la farine déshuilée ou non, le tourteau, le fromage, le lait de soja.

Une analyse de graines importées ell France donne :

Matière sèche ............. . 90

Protéine $. \ldots \ldots \ldots \ldots \ldots \ldots \ldots \ldots . \ldots \ldots$

Extrait éthéré $\ldots \ldots \ldots \ldots \ldots \ldots \ldots$ I8

Cellulose ............... . 5

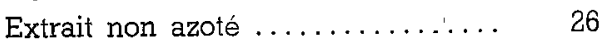

$\mathrm{Ca} \% \%^{\circ} \ldots \ldots \ldots \ldots \ldots \ldots \ldots \ldots . \ldots \ldots$

$\mathrm{P} \%{ }^{\circ} \ldots \ldots \ldots \ldots \ldots \ldots \ldots \ldots \ldots \ldots$

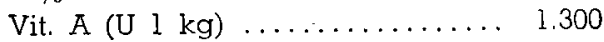

Vit. Bl $(y / \mathrm{kg}) \ldots \ldots \ldots \ldots \ldots \ldots . \ldots 2.400$

Vit. B2 $(r / \mathrm{kg}) \ldots \ldots \ldots \ldots \ldots \ldots . .2 .800$

Après extraction de l'huile, la farine donne, pour trois échantillons du Nyasaland :

$\begin{array}{lrrrr}\text { Eau } \ldots \ldots \ldots \ldots \ldots \ldots \ldots \ldots & 12,8 & 10,6 & 10,8 \\ \text { Proteine. } \ldots \ldots \ldots \ldots \ldots \ldots \ldots & 41,6 & 52,6 & 47,1 \\ \text { Extrait éthéré } \ldots \ldots \ldots \ldots \ldots & 9 & 2,1 & 3 \\ \text { Cellulose } \ldots \ldots \ldots \ldots \ldots \ldots \ldots & 5,4 & 5,4 & 5,4 \\ \text { Extrait non azoté } \ldots \ldots \ldots \ldots \ldots & 33,7 & 23,9 & 29,6 \\ \text { Cendres } \ldots \ldots \ldots \ldots \ldots \ldots \ldots & 5,6 & 5,4 & 6,8\end{array}$

Entre deux échantillons de tourteaux importés, les différences sont les suivantes :

\begin{tabular}{|c|c|c|}
\hline Matière sèche. & $\begin{array}{c}\text { Pression } \\
91\end{array}$ & $\begin{array}{c}\text { Extraction } \\
89\end{array}$ \\
\hline Protéine $\ldots \ldots \ldots \ldots \ldots \ldots$ & 41 & 45 \\
\hline Extrait éthéré $\ldots \ldots \ldots \ldots \ldots$ & 8 & 4 \\
\hline Cellulose .............. & 4,5 & 4,7 \\
\hline Extrait non azoté $\ldots \ldots \ldots \ldots$. & 36,5 & 40 \\
\hline $\mathrm{Ca} \ldots \ldots \ldots \ldots \ldots \ldots \ldots \ldots$ & 2,5 & 2,6 \\
\hline$\ldots \ldots \ldots \ldots \ldots \ldots$ & 65 & 6,6 \\
\hline
\end{tabular}

Dans l'un, la teneur en vitamine $A$ est de $240 \mathrm{~kg}$ pour $100 \mathrm{~g}$.

Les protides se répartissent de la façon suivante (p, 100 sur la base de 16 p. 100 d'azote) :

Arginine : 7,1 ; cystine : 1,9; histidine : 2,3; isoleucine : 4,7 ; leucine $: 6,6$; lysine : 5,8 ; methionine : ?; phenylalanine : 5,7 ; thréonine : 4 ; tryptophane : 1,$4 ;$ tyrosine : 4,$1 ;$ valine : 4,2

Le lait de soja est surtout utilise dans l'alimentation humaine; les procédés de fabrication sont assez variés; de façon générale, les fèves sont broyées avec un peu d'eau, après avoir été lavées et mises à gonfler pendant 10 à 24 heures. La bouillie est ensuite extraite avec de l'eau ou des solutions alcalines légères, le poids du liquide ne dépassant pas huit fois celui des fèves utilisées. Le 'résidu insoluble est séparé sur un filtre en tissu ou par centrifugation; le liquide est ensuite bouilli 20 minutes. La composition de divers laits de soja par rapport au lait de vache est la suivante.

Eau Protéine Graisse: H.deC. Cendres

Lait de soja ..... 89 à 3,02 à 2 à 0,04 à 0,41 à

$\begin{array}{lllll}92,5 & 4,95 & 2,97 \cdot 3,02 & .0,50\end{array}$

$\begin{array}{lllllll}\text { Lait de vache } \ldots & \ldots & 87,3 & 3,42 & 3,67 & 4,78 & 0,73\end{array}$

On obtient aussi un « lait » en faisant tremper pendant 12 heures les graines grossièrement broyées dans 8-10 fois leur poids d'eau; on écrase ensuite le mélange entre des meules, on filtre sur toile et on ajoute 2-3 cuillerées de lactose et 1 cuillerée de sel par litre de breuvage.

On a aussi fabriqué, pour l'alimentation des poulains, un lait artificiel obtenu avec la farine de Soja; le mélange est le suivant : eau bouillie 90 p. 100 ; Soja : 10 p. 100; à cette dilution on ajoute, par kilog, $70 \mathrm{~g}$ de tourteau d'arachides, $50 \mathrm{~g}$ de sucre et $\mathrm{du}$ sel, ce qui d'après de GoLDFIEM constitue un' liquide alimentaire voisin comme composition du lait de jument.

\begin{tabular}{|c|c|c|}
\hline golstithatis & ! & à base de soja \\
\hline Vatières azotées. & $2 ; 18$ & 2.21 \\
\hline Iatières grasses. & 0,55 & 0,54 \\
\hline tose $\ldots \ldots \ldots$ & 5,50 & 5 \\
\hline is & 0,40 & 0,41 \\
\hline drates de carbone ... & $\gg$ & 1,47 \\
\hline ellulose . . . . . . . . & $\gg \vdots$ & 0,21 \\
\hline$\ldots \ldots$ & 91,37 & 90,16 \\
\hline
\end{tabular}

On utilise aussi, sur place, et pour l'alimentation des porcs, la boullie qui subsiste après fabrication du fromage de soja.

Les "laits " constituent en général un liquide jaunâtre, à odeur de malt, acide, coagulant comme le lait en présence des acides, en raison de la glycinine. 
Les tourteaux sont utilisés chez les divers animaux, surtout chez les vaches laitieres, On leur reproche de donner un beurre mou.

On sait que l'addition de viande ou de lait desséché à une ration de céréales augmente la résistance des poulets à l'ascaridiose. Le même résultat est obtenu quand, au lieu de viande ou de lait, on ajoute de la farine de tourteau de soja.

Les gousses et graines sont aussi données aux divers animaux de la ferme.

La farine de soja déshuilée est un aliment protéique de valeur égale aux meilleures céréales, ainsi que l'ont montré les études du coefficient d'utilisation pratique des légumineuses. Les expériences de $T$. Zucker et L. Zucker ont d'autre part indiqué que le mélange de farine de soja, d'arachide et de coton constitue un aliment concentré en protéines, riche en vitamines du complexe $B_{1}$ en riboflavine et en acide nicotinique. On l'utilise chez les divers animaux. Elle peut entrer dans la ration des jeunes poulets dans la prcportion de 35 p. 100.

Qu'il s'agisse des graines, des tourteaux, de la farine, on observe au bout d'un certain temps particulièrement chez les veaux et les vaches en lait, des accidents de divers ordres, lelle la " maladie de Duren ».

Expérimentalement, on a pu démontrer chez le rat l'existence dans la farine d'un facteur générateur de goitre : une ration renfermant 85 à 90 p. 100 de farine amène en quelques semaines une hypertrophie thyroïdienne considérable; cette action dépend peu de la teneur en iode de la ration, cependant, on contrarie l'action du facteur goitrogène par l'iode et ce facteur est très diminué par la chaleur ou par le traitement de la farine à l'aide d'éther ou d'acétone. Quand on alimente les volailles avec une ration renfermant 25 p. 100 de farine de tourteau, on provoque au bout d'un certain temps l'apparition du goitre.

Outre ses propriétés goitrogènes, et probablement en raison de celles-ci, la farine de soja affaiblit les facultés de reproduction; la viabilité, l'état physique des poussins sont diminués, ainsi que le taux des naissances. Le remplacement de la farine par d'autres protéines, et surtout de la viande, supprime pour bonne part ces inconvénients.

Les graines de soja contiennent d'autre part un agent inhibiteur de la protéolyse; ce dernier étant sensible à la chaleur, le traitement thermique augmente la valeur nutritive des graines (comme celle des graines de haricot); aussi chez les volailles comme chez le porc, la cuisson est-elle indiquée; chez ce dernier, le soja non traité donne un lard mou. Chez le jeune rat, il provoque à la longue de la nécrose hépatique, signe d'une déficience en acides aminés puisque l'adjonction de cystine et de méthionine évite ou guérit cet accident.

La " maladie de Duren " affecte les veaux et les vaches laitières : anorexie, apathie, élévation de la température, hémorragies. L'alimentation à la farine de soja en serait la cause. Expérimentalement, on ne reproduit pas toujours la maladie; cela parait tenir à ce que la teneur de la farine en méthionine est variable et que c'est la carence en méthionine qui serait la cause des accidents.

Les accidents observés ont donné lieu à diverses interprétations.

Pour certains, la graine entière exerce une action gênante, soit sur la provitamine A soit sur son utilisation par le bétail. Pour d'autres, la sojine, protéine toxique de la graine de soja, entre pour environ la moitié dans l'action inhibitrice de la croissance chez les rats d'expérience, l'autre moitié a un effet qui peut être contrarié par la trypsine. On pourrait déceler dans l'extrait aqueux de la graine, une substance qui inhibe non seulement la trypsine mais aussi la papaine. L'enzyme protéolytique de la farine de blé peut aussi être affecté.

Les travaux des récentes années simplifient la question. L'observation montre qu'il existe, quant à la valeur nutritive des graines ou du tourteau, de grandes différences selon que le produit a subi ou non un traitement thermique, l'amélioration ne se manifestant que si le chauffage se fait en présence d'eau; seuls les tourteaux traités à une haute température et en présence d'eau ont une efficacité protidique suffisante.

Cela s'expliquerait par la présence d'une substance toxique thermolabile. Il s'agirait d'une antitrypsine qui inhibe l'action de la trypsine. Cette antitrypsine pourrait être neutralisće par la méthionine, l'addition de cet aminoacide causant le même effet que le chauffage.

Dans des échantillons de tourteau de couleus foncée, la proportion de protéine non digestible ost importante, ce qui traduit l'inconvénient du surchauffage.

Le tourteau par ailleurs ne doit pas contenir plus de 15 p. 100 d'acide gras libre (dans la matière grasse).

\section{Genre Sesbania}

Les diverses espèces spontanées ou cultivées, dont les feuilles et les tiges donnent un fourrage de valeur diverse, , peuvent aussi fournir leurs 
graines dont la composition est la suivante (Afrique du Sud) :

\begin{tabular}{|c|c|c|c|}
\hline \multirow[b]{3}{*}{ 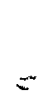 } & \multirow[b]{2}{*}{ Eau } & \multicolumn{2}{|c|}{ S. cinerascens $\$$ mossambicensis } \\
\hline & & 11,4 & 9,6 \\
\hline & Protéine & 21,7 & 32,9 \\
\hline & Extrait éthéré $\ldots \ldots \ldots \ldots$ & 4,8 & 6,2 \\
\hline & Cellulose $\ldots \ldots \ldots \ldots \ldots$ & 12,2 & 10,9 \\
\hline & Extractif non azoté ....... & 47,0 & 39,0 \\
\hline & Cendres $\ldots \ldots \ldots \ldots$ & 2,9 & 1,4 \\
\hline
\end{tabular}

\section{Genre Sophora}

Nous avons vu que diverses espèces du genre ont des feuilles comestibles, et que certaines sont accusées de toxicité, surtout par leurs graines. Celles de $S$. secundiflora, au Texas, pourraient cependant être données aux animaux. Elles contiennent :

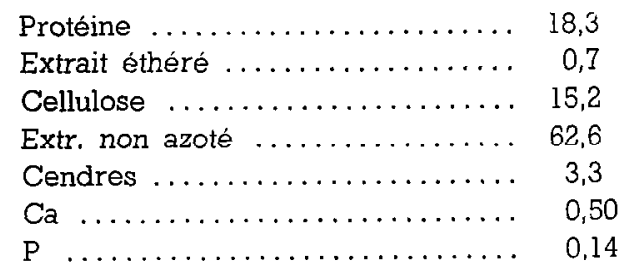

\section{Genre Swartzia}

Swartzia madagascariensis est répandue en Afrique occidentale et méridionale, à Madagascar. Voici deux analyses des gousses (Rhodésie du Sud).

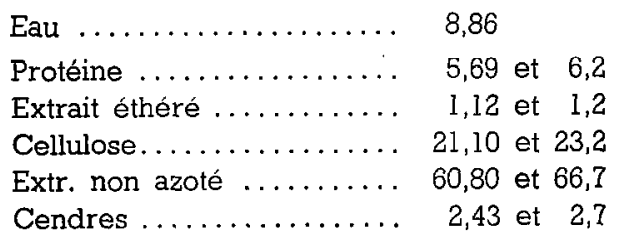

\section{Genre Tamarindus}

Le tamarinier, $T$. indica, dans l'Inde comme en Afrique, voit non seulement ses feuilles, mais ses fruits mangés par le bétail.

Les graines décortiquées de Tamarindus indica contiennent :

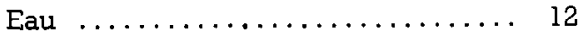

Protéine ..................... 16

Extrait éthéré $\ldots \ldots \ldots \ldots \ldots \ldots \ldots$ 6. 6,5

Cellulose brute ................ 3,8

Extractif non azoté ............ 58,9

Cendres $\ldots \ldots \ldots \ldots \ldots \ldots \ldots \ldots, \quad 2,8$

\section{Genre Vicia}

- Les graines des diverses vesces cultivées en régions subtropicales ont la composition moyenne suivante

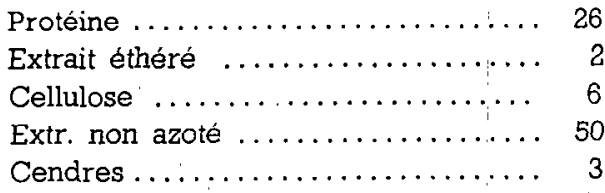

Celles de Vicia faba cultivé au Soudan renferment :

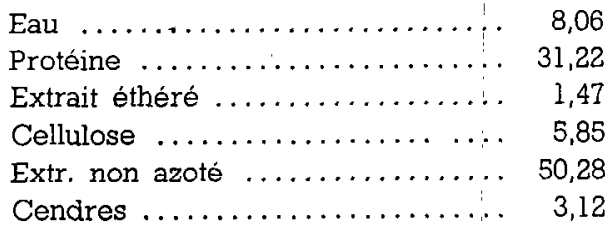

La composition moyenne des fèves est la suivante :

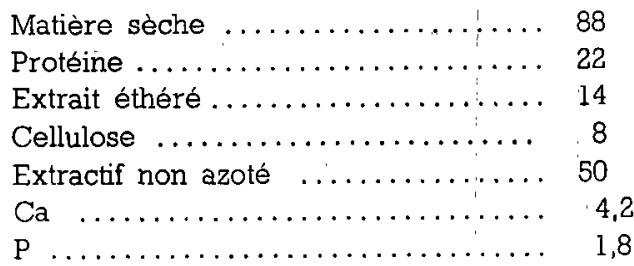

La teneur en vitamines est

Vit. A (U.I. $/ \mathrm{kg}) \ldots \ldots \ldots \ldots \ldots \ldots, 300$

Vit. Bl $(\gamma / \mathrm{kg}) \ldots \ldots \ldots \ldots \ldots \ldots, 500$

Vit. $B 2(\gamma / \mathrm{kg}) \ldots \ldots \ldots \ldots \ldots \ldots . . \ldots 180$

\section{Genre Vigna}

Nous avons vu l'importance de diverses espèces du genre comme fourrage et leur diffusion dans la plupart des régions tropicales. De toutes, c'est Vigna catjang (= sinensis) qui est la plus répandue. Si la plante est surtout cultivée comme fourrage, la graine est un bon aliment surtout pour les bovins et les moutons. Nous en avons également donné aux chevaux au Soudan. La variété blanche parait à ce point de vue la meilleure.

Les graines de Vigna sinensis ont la valeur alimentaire des " pois" d'autres espèces; mais la maturité se fait irrégulièrement, en sorte que la cueillette doit souvent être faite à la main à mesure que les graines mûrissent; c'est une des raisons pour lesquelles la culture du « cow pea 》 est surtout pratiquée pour l'obtention de fourrage. Cependant les graines peuvent être un excellent complément pour les céréales et elles sont plus riches que d'autres en vitamine $A$. On peut y avoir recours pour l'engraissement des divers animaux de la ferme.

Dans la ration des bovins, on peut les donner en remplacement du tourteau de graines de coton, en tenant compte de ce que leur teneur en protéine 
est de 20 à 25 p. 100 alors que le tourteau en renferme 40 p. 100 et plus.
L'analyse de divers échantillons donne les résultats suivants :

\begin{tabular}{|c|c|c|c|c|c|c|c|c|}
\hline Origine & Eau & Protéine & $\begin{array}{l}\text { Extrait } \\
\text { étheré }\end{array}$ & Cellulose & $\begin{array}{c}\text { Extractif } \\
\text { non azoté }\end{array}$ & Cendres & $\mathrm{CaO}$ & $\mathrm{P}_{2} \mathrm{O}_{5}$ \\
\hline Rhodésie Sud. & 43,9 & 23,4 & 1,8 & 5,9 & 51,6 & 3,4 & - & $=-$ \\
\hline Sierra Leone : & $.11,3$ & 24,3 & 1,1 & 4,9 & 55,2 & 3,2 & - & - \\
\hline Tanganyika ... & - & 24,49 & 0,95 & 5,57 & 65,67 & 3,32 & 0,66 & 1,49 \\
\hline Soudan ... & 7,95 & 20,61 & 1,63 & 2,76 & 64,07 & 2,98 & - & - \\
\hline
\end{tabular}

Les cosses renferment 7 p. 100, de protéine, 1,2 p. 100 de matière grasse, 40 p. 100 de cellulose.

\section{Genre Voandzeia}

Le pois bambara, Voandzeia subterranea, et l'espèce voisine $V$. poissonii $(=$ Kerstingiella geocarpa) ont des graines qui vont surtout à l'alimentation humaine, mais qu'on donne aussi aux animaux, surtout aux petits ruminants. Nous en avons donné au cheval. Pour le distribuer on concasse cosses et graines. L'enveloppe, épaisse, est ainsi morcelée.

Décortiquées, les graines de Kerstingiella geo- carpa renferment (deux échantillons d'Afrique occidentale) :
Eau $\ldots \ldots \ldots \ldots \ldots \ldots \ldots, 0,0$ et 10,4
Protéine ............ 18,00 et 21,4
Matière grasse $\ldots \ldots \ldots \ldots, 2,15$ et 1,90
Cellulose............. 3,96 et 12,70
Extrait non azoté ...... 63,12 et 48,9
Cendres ............ 2,83 et 4,30

Les analyses de divers échantillons de Voandzeia subterranea donnent les résultats suivants :

\begin{tabular}{|c|c|c|c|c|c|c|c|c|c|}
\hline Produit & Origine & Eau & Protéine & $\begin{array}{l}\text { Extrait } \\
\text { étheré }\end{array}$ & Cellulose, & $\begin{array}{c}\text { Extractif } \\
\text { non azoté }\end{array}$ & Cendres & $\mathrm{CaO}$ & $\mathrm{P}_{2} \mathrm{O}_{5}$ \\
\hline Pois entier. . & Soudan & & 21,2 & 5,7 & 3,2 & 58,3 & 3,3 & - & - \\
\hline- & . - & $\cdots$ & 21,4 & 6,1 & 3,1 & 57,9 & 3,3 & - & - \\
\hline- & Zanzibar & $\cdots$ & 19,1 & 6,5 & 4,2 & 58,9 & 3,5 & - & - \\
\hline - & Nigeria & -- & 16,0 & 6,2 & 3,9 & 58,4 & 2,4 & - & - \\
\hline- & Gold Coast & $\cdots$ & 20,49 & 6,86 & 4,29 & 65,07 & 3,29 & 0,19 & 0,81 \\
\hline Enveloppe . & - & & 6,05 & 1,28 & 31,65 & 53,0 & 2,02 & 0,38 & 0,31 \\
\hline Amande....... & - & $\ldots$ & 21,38 & 7,29 & 1,49 & 66,53 & 3,31 & 0,04 & 0,93 \\
\hline
\end{tabular}

\section{Genre Vouacapoua}

Les gousses de $V$. anthelmintica sont mangées par le bétail au Brésil ; le reste de la plante_est dangereuse.

\section{LILIACÉES}

\section{Genre Smilax}

Ce genre (tribu des Smilacées) comprend divere arbrisseaux qu'on trouve notamment dans les
" maquis " méditerranéens, en Amérique du Nord Le bétail les broute. Les fruits sont comestibles. Ceux de $S$. glauca contiennent :

Protéine ................. 10,2

Extrait éthéré $\ldots \ldots \ldots \ldots \ldots \ldots \ldots, 7,5$

Cellulose $\ldots \ldots \ldots \ldots \ldots \ldots \ldots \ldots \quad 18,6$

Extr. non azoté $\ldots \ldots \ldots \ldots \ldots \ldots .60,8$

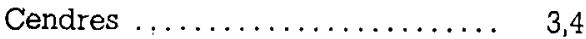

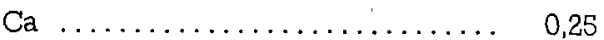

P $\ldots \ldots \ldots \ldots \ldots \ldots \ldots \ldots \ldots, 0,16$ 


\section{MALPIGHICEES}

\section{Genre Malpighia}

- Les arbres de ce genre, d'Amérique, ont des fruits comestibles (cerises des Antilles); Malpighia glabra, $M$. punicifilia notamment. Le fruit de la dernière espèce est la cerise de Cayenne, qui a - été introduite en Afrique. Ce fruit habituellement réservé à la consommation humaine, est parfois mangé par les moutons et les chèvres. Il est une source exceptionnelle de vitamine C (1326 mg pour $1.000 \mathrm{~g})$.

\section{MALVACÉES}

\section{Genre Gossypium}

Les divers cotons fournissent des graines auxquelles adhère la fibre textile. Le tégument de la graine est une coque épaisse. La séparation de la fibre (délintage) laisse une graine plus ou moins parfaitement dénudée. Après cette opération, on décortique pour extraire l'huile de l'amande, ce qui laisse un tourteau. Ce n'est pas une règle générale II existe des tourteaux qui renferment encore beaucoup de fibres et d'enveloppes (tourteaux bruts cotonneux), d'autres dépourvus de lint, mais non décortiqués, ou semi-décortiqués. Les produits livrés à l'alimentation sont donc variés : graine intacte, coques, tourteaux variés, farines tirées de ces tourteaux. Comme les tourteaux, les farines varient d'aspect selon que l'extraction de la coque a été plus ou moins complète.

Les inconvénients que peuvent présenter les produits sont de deux ordres, selon qu'ils tiennent à la présence de fibres ou à la toxicité propre du produit.

Le lint provenant des graines, mal défibrées, pourrait amener la formation d'aegagropiles, d'où obstructions intestinales mortelles. Le danger a été exagéré. Moussu faisait déjà remarquer qu'on n'a guère signalé d'obstructions que chez l'agneau. Bien des observateurs ont montré qu'on ne retrouve aucun duvet dans l'intestin d'animaux alimentés assez longtemps avec les graines.

Én ce qui concerne la toxicité, on l'attribue à diverses substances renfermées en faible quantité : bétaïne, choline, neurine, mais il semble bien que les inconvénients du tourteau tiennent surtout, d'une part à la présence du gossypol de la graine, et d'autre part au passage dans la matière grasse du lait d'un chromogène contenu dans l'huile de coton; ce dernier inconvenient est de peu d'importance.
Le gossypol est un composé phénolique insoluble dans l'eau, soluble dans l'huile et les alcalis, neutralisé par la chaleur et l'oxydation.

La teneur en gossypol est très variable : de 0,39 à 1,70 p. 100 de la matière sèche; cette teneur paraît avoir un caractère génétique; elle est aussi sous la dépendance des conditions de culture et d'extraction de l'huile.

La sensibilité du gossypol à la chaleur est utilisée pour " détoxiquer " les farines et tourteaux; la transformation en gossypol D est surtout obtenue par la chaleur humide en présence d'alcalins ou de sels, les alcalins étant préférables, et parmi eux la soude.

De nombreux essais réalisés avec des variétés privées de gossypol et provenant de traitements divers (pression ou solvant), le traitement thermique etant varié, montrent que, la teneur en protéine variant entre 34 et 58 p. 100, les meilleurs résultats (chez le poulet du moins) sont obtenus avec les échantillons ayant subi les températures les plus basses. Le chauffage ne doit pas dépasser $93^{\circ} \mathrm{C}$ la meilleure température étant $70^{\circ} \mathrm{C}$. On peut alors distribuer à des poussins des farines renfermant 0,108 p. 100 de gossypol, la farine constituant 40 p. 100 de la ration; la proportion peut être portée à 70 p. 100 si la teneur en gossypol n'est que de 0,02 p. 100. D'ailleurs, le gossypol, résistant à la digestion, est rejeté en grande partie : chez des rats nourris à la farine de coton, on retrouve dans les fèces 86 p. 100 du gossypol.

L'élimination mécanique des glandes supprime l'élément toxique. Si on ajoute les glandes isolées à une ration ne renfermant pas de graines de coton, la croissance chez les volailles quil la reçoivent est diminuée, ce qui semble indiquer que l'agent toxique est présent dans les glandes et n'est pas le produit d'une réaction entre les protéines de la farine des graines et celles des glandes. Seuls le gossypol et la gossypurpurine peuvent être extraits en quantité appréciable des glandes. $\mathrm{Si}$ on les ajoute à l'etat pur à une ration, il n'y a pas d'influence marquée sur l'accroissement des poulets, il y a cependant une légère corrélation entre la valeur nutritive de la farine de graine et sa teneur en gossypol et gossypurpurine.

Pour certains, l'expérience montre que la toxicité du pigment des glandes serait due à un constituant des glandes différent du gossypol et de la gossypurpurine, ou qui s'ajoute à eux.

La toxicité n'est pas proportionnelle à la contenance en gossypol; le chauffage à sec ne réduit pas la toxicité, alors que le chauffage en présence 
d'eau la réduit de 50 p. 100 environ; lo matériel toxique est entièrement extrait par l'acétone.

On sait aussi que le gossypol a pour effet d'amener la décoloration du jaune de l'œuf chez les poules: C'est ainsi que si on ajoute de 0,001 p. 100 à 0,008 p. 100 de gossypol libre à une ration de poules pondeuses, on voit apparaître cette décoloration dans une proportion d'autant plus grande que la dose est plus forte. Elle est beaucoup plus grande chez les cufs conservés que chez les oufs frais.

Pour d'autres auteurs, les accidents tiennent aussi à la carence en vitamine $A$ et en vitamine $D$.

De façon générale, le danger est nul si la proportion de tourteau ne dépasse pas 10 p. 100 de la ration. Chez des porcs auxquels on donne une ration comportant 20 p. 100 de tourteau non « détoxiqué », on observe de la paraplégie, de la diarrhée. Avec un tourteau qui renferme de $0,16 \mathrm{p}, 100$ à 0,18 p. 100 de gossypol, on peut causer de la gastroentérite hémorragique chez le boeuf et le porc. Les accidents ne surviennent que si on dépasse la dose de $3 \mathrm{~kg}$ chez le bceuf et $0,500 \mathrm{~kg}$ chez le porc.

Il faut par ailleurs noter que, à l'inverse du tourteau de soja que le traitement thermique améliore, le tourteau de coton peut être altéré par la chaleur : l'autoclavage d'une heure diminue de beaucoup la valeur par alteration des protides.

L'analyse de deux échantillons de graines de coton du Tanganyika donne les résultats suivants :

\begin{tabular}{|c|c|}
\hline Protéine $\ldots$. & 14,72 \\
\hline Matière grasse & 16,87 \\
\hline Cellulose.............. & 28,29 \\
\hline Extractif non azote....... & 35,74 \\
\hline Cendres ............... & 4,38 \\
\hline $\mathrm{Ca} 0$. & 一 \\
\hline P2 05 & - \\
\hline
\end{tabular}

La composition de l'amande est en moyenne de :

Eau $\ldots \ldots \ldots \ldots \ldots \ldots \ldots \ldots \ldots \ldots$

Protéine $\ldots \ldots \ldots \ldots \ldots \ldots \ldots \ldots \ldots . . \ldots$

Matière grasse .............. 30

Cellulose $\ldots \ldots \ldots \ldots \ldots \ldots \ldots \ldots \ldots \quad 5$

Extractif non azoté $\ldots \ldots \ldots \ldots \ldots \ldots 15$

Cendres .................. 7

Celle de l'enveloppe

Eau $\ldots \ldots \ldots \ldots \ldots \ldots \ldots \ldots \ldots \ldots, 10$

Protéine ................ 4

Matière grasse .............. 1

Cellulose $\ldots \ldots \ldots \ldots \ldots \ldots \ldots \ldots \ldots, 48$

Extractif non azoté ............. 35

Cendres.................... 3
L'enveloppe des graines de coton de Russie a la composition moyenne suivante

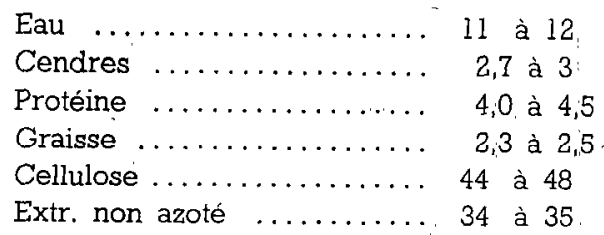

Comparativement, l'enveloppe de graines' du Pakistan contient :

\begin{tabular}{|c|c|c|}
\hline Eau & & 4,5 \\
\hline Cendres & *. & 3,4 \\
\hline Protéine & $\ldots$ & 3,9 \\
\hline Graisse & & 2,0 \\
\hline Cellulose & & \\
\hline xtr. & l azoté & \\
\hline
\end{tabular}

La faible teneur en $\mathrm{Ca}$ et $\mathrm{P}$ justifie la supplémentation en herbe et minéraux.

Il y a, concernant la composition de la graine et de l'enveloppe (habituellement dénommée coque), des variations assez grandes.

Pour la graine, on signale pour les protéines des chiffres de 14 à 26 p. 100, les graisses de 16 à 22 p. 100 . la cellulose de 27 à 30 p. 100 ; les hydrates de carbone de 25 à 35 p. 100; les cendres de 4 à 6 p. 100 .

La composition des tourteaux et des farines est très variable, selon qu'ils proviennent de graines décortiquées ou non, selon les modes de fabrication. En moyenne, les différences sont les suivantes:

Eau Prot. Graisse H. de C. Cellul. Cend. Tourteau non décortiqué. $\begin{array}{lllllll}12 & 24 & 6 & 33 & 21 & 5\end{array}$

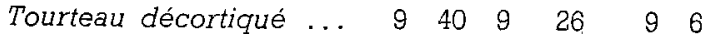

D'autres analyses indiquent :

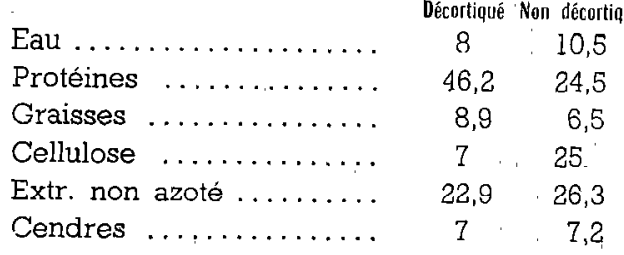

Un tourteau du Tanganyika, renfermant tine certaine proportion de coques, donne

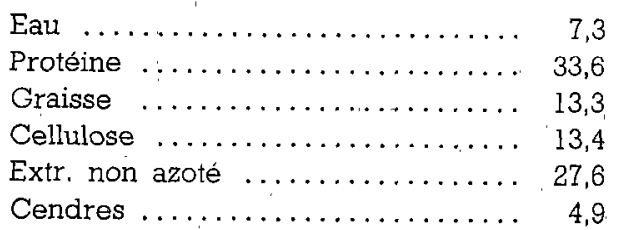

Les acides aminés sont ceux qu'on trouve dans la farine de soja, la farine d'arachide. La teneur en lysine, méthionine et tryptophane est, pour certains, plus grande dans la farine de coton que dans les 
deux autres. Calculèes sur la base de 16 p. 100 d'azote, les proportions sont les suivantes : Arginine, 7,4 ; cystine : 2 ; histidine : 2,6 ; isoleucine : 3,3 ; leucine, 5 ; lysine : 2,7 ; méthionine : 2,1 ; phenylalanine $: 6,8$; thréonine $: 3$; tryptophane $: 3,4$; valine : 3,7 .

Dans des échantillons renfermant 48,4 p. 100 de protéines, 32,1 p. 100 de ces protéines sont représentés par les huit principaux acides aminés, la méthionine et la cystine étant les plus faibles. D'autre part, les divers acides aminés n'ont pas le même coefficient de digestibilité; arginine 93 p. 100; lysine $64 \mathrm{p} .100$; méthionine $67 \mathrm{p}$. 100. Il y a donc faiblesse en divers acides aminés essentiels, particulièrement en lysine.

La teneur en phosphore est grande; nous avons indiqué 1,85 p. 100 ; elle peut être de 1,10 p. 100 ; le calcium, par contre est pauvre : 0,22 ou 0,32 p. 100.

En ce qui concerne les vitamines, il y a peu de carotène, mais il est riche en vitamines du groupe B. Pour $100 \mathrm{~g}$, il y a : riboflavine : $1.020 \mathrm{\gamma}$; thiamine : $1.400 \gamma$.

La graine donnée entière n'est pas dangereuse si elle est mangée à une dose normale ; des accidents surviennent parfois quand un animal échappé mange une quantité anormale.

Chez les bovins, Malfroy qui a expérimenté au Soudan estime qu'on peut en donner jusqu'à $1,500 \mathrm{~kg}$ chez les animaux de $500 \mathrm{~kg}$; il faut éviter d'en donner aux jeunes bêtes récemment sevrées, aux vaches en gestation pendant les 4 semaines qui précedent le vêlage puis pendant qu'elles allaitent. Des essais faits au Maroc ont montré qu'on pourrait se montrer moins réservé quant aux quantités à distribuer : le bétail alimenté avec $10 \mathrm{~kg}$ de betteraves et 2 à $3 \mathrm{~kg}$ de graines moulues s'est maintenu en bon état; on peut aussi donner $1 \mathrm{~kg}$ de graines pour 12 à $15 \mathrm{~kg}$ d'ensilage.

Quant à une ration bien équilibréc et comprenant du vert, on ajoute des graines de coton, on donne une augmentation légère et temporaire du lait ef de la matière grasse (chez la bufflesse); il y a baisse, au contraire, si les graines sont ajoutées à une ration ne renfermant pas de vert. Cependant l'expérimentation montre que l'huile de graines de coton ne peut remplacer la matière grasse du lait dans l'alimentation du veau; les animaux qui reçoivent du lait écrémé additionné d'huile de coton hydrogénée croissent moins vite que ceux qui reçoivent le lait entier.

Chez le porc à l'engrais, l'introduction de 10 à 25 p. 100 de graines de coton dans la ration donne de mauvais résultats, le taux le plus fort peut causer la mort au bout d'un certain temps; au-dessus, on peut observer de l'inappétence, un mauvais rendement de la ration.
Il semble bien que l'emploi de la graine est maintenant assez répandu pour permettre de conclure que, pour les graines entières comme pour la farine déshuilée ou non et pour le tourteau, ces produits peuvent être donnés sans risques à condition qu'on ne dépasse pas une quantité donnée.

La farine non déshuilée, qui contient 36 à 41 p. 100 de matières azotées et 8 p. 100 d'huile, est un aliment très riche. Elle est précieuse pour la production du lait et l'engraissement; elle a la réputation de durcir la graisse corporelle et le beurre. Elle peut être échauffante pour les jeunes bovins et le porc, chez lequel il ne faut pas dépasser $0,500 \mathrm{~kg}$ par jour.

Dans des groupes de vaches de races différentes qui reçoivent une ration déterminée, le remplacement d'une partie de l'aliment concentré par de la graine de coton poids pour poids, et le concentró étant donné proportionnellement à la production laitière ( $1 \mathrm{~kg}$ pour 3 a $5 \mathrm{~kg}$ de lait produit) on observe une augmentation de la teneur en beurre pendant les périodes où est donnée la graine de coton. Au bout de 56 jours, cette augmentation est de 0,13 p. 100 dans un groupe, de 0,24 p. 100 dans un autre. Il y a une légère diminution de la matière sèche non grasse. La quantité de lait produite ne varie pas. La viscosité du beurre est augmentée. Le lait de bufflesse consommant une assez forte quantité de graines de coton est particulièrement riche en acides stéarique et oléique.

L'alimentation des poules à la farine de graines de coton rendrait l'albumine de l'œuf aqueuse; le jaune porte des taches noirâtres ou brunes; tous les cufs portent ces altérations quand la farine entre dans la proportion de 15 p. 100 de la ration et la proportion des éclosions diminue. La production des ceufs baisse de moitié. On observe aussi do la décoloration du jaune quand la proportion de farine atteint 20 p. 100 de la ration.

La farine de graines de coton privée des pigments glandulaires, donnée aux poulets comparativement à la farine ordinaire ou à la farine de tourteau de soja, se montre supérieure aux deux autres produits pour la croissance et la fécondité des ceufs. Si on ajoute d̀ la farine de soja, les glandes pigmentaires qui contiennent du gossypol et de la gossypurpurine, on obtient le même résultat.

Pour combattre l'action du gossypol on peut ajouter du sulfate de fer, mais cela diminue la production des ceufs.

La farine de graines de coton a'été accusée de causer des désordres graves et parfois l'avortement chez des brebis qui en absorbaient $225 \mathrm{~g}$ par jour, mais des expériences ultérieures ont montré qu'il n'en est rien. 
Le tourteau décortiqué traité pour éliminer le gossypol est utilisable chez le porc à condition de ne pas dépasser 10 p. 100 de la ration, chez les poules avec la même précaution, et surtout chez les vaches laitières. Son emploi à ce titre montre que ses effets sur les produits laitiers sont les suivants : le lait est normal en ce qui concerne la teneur en matière grasse ef la matière sèche totale. La coloration jaune est nulle ou peu marquée et le beurre a une odeur légèrement forte. La crème monte un peu plus lentement et dans la plupart des cas le volume de crème est diminué par rapport à la teneur en matière grasse. Cette crème est peu colorée, de même que le beurre; le temps de barattage est prolongé.

Les enveloppes, parfois utilisées pour la fabrication d'un papier grossier, peuvent aussi constituer un fourrage de valeur sensiblement égale à celle de la paille: on les incorpore aussi à la farine de graines. Leur valeur alimentaire équivaudrait à $207 \mathrm{~kg}$ d'ensilage de maïs ou $250 \mathrm{~kg}$ d'ensilage de mil. On peut en donner environ $15 \mathrm{~kg}$ aux gros bovins, 6 à 8 aux bovins de $\mathrm{l}$ à 2 ans, 3 à $5 \mathrm{~kg}$ aux veaux, 1 à $1,500 \mathrm{~kg}$ aux moutons (remplacement de 50 à 75 p. 100 de la luzerne). Il est prudent de retirer le produit de la ration pendant un certain temps, tous les trois mois environ.

\section{Genre Hibiscus}

Les feuilles de la plupart des espèces sontmangées : plusieurs de ces espèces ont des graines oléagineuses. Celles de l'Okra, $H$, esculentus, ont la composition suivante,
Protéine $\ldots \ldots \ldots \ldots \ldots \ldots \ldots \ldots \ldots 24,7$

Extrait éthéré $\ldots \ldots \ldots \ldots \ldots \ldots \ldots \ldots 19 \ldots \ldots \ldots$

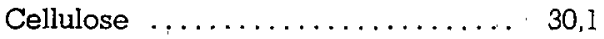

Extr, non azoté $\ldots \ldots \ldots \ldots \ldots \ldots \ldots 20,6$

Cendres ................. 4,9

L'huile ressemble à l'huile de graines de coton et à celle des graines de Chrozophora clicata. Le résidu n’a pas été expérimenté.

Les graines d' $H$. sabdariffa, espèce qui a gagné à peu près toutes les zones tropicales, renferment :

\begin{tabular}{|c|c|}
\hline Eau & 7,4 \\
\hline Protéine $\ldots \ldots \ldots \ldots \ldots \ldots \ldots$ & 26,8 \\
\hline Extrait éthéré $\ldots \ldots \ldots \ldots \ldots \ldots \ldots$ & 19,8 \\
\hline Cellulose ...... & 15,5 \\
\hline Extr. non azoté . . & 25,2 \\
\hline Cendres $\ldots \ldots \ldots \ldots \ldots \ldots \ldots \ldots$ & 5,0 \\
\hline
\end{tabular}

Le " dâ ", Hibiscus canabinus, répandu comme plante textile en Afrique occidentale, a une graine qui fournit une huile siccative. Le tourteau serait un bon aliment, mais sa production ne peut être que limitée.

\section{Genre Theobroma}

Le fruit de Theobroma cacao est rarement donné entier aux animaux après concassage. Par contre. il fournit à l'alimentation animale divers sous-produits de valeur : le tourteau, résidu de l'extraction du beurre de cacao (par pression hydraulique surtout), tourteau provenant des fruits entiers ou décortiqués; la farine provenant de ces deux variétés de tourteaux, les coques concassées ou pulvérisées, qui proviennent du décorticage. Voici quelques analyses de ces produits.

\begin{tabular}{|c|c|c|c|c|c|c|c|c|c|}
\hline Nature & Origine & Eau & $\begin{array}{l}\text { Pro- } \\
\text { teine }\end{array}$ & $\begin{array}{l}\text { Extrait } \\
\text { éthéré }\end{array}$ & $\begin{array}{l}\text { Cellu- } \\
\text { lose }\end{array}$ & \begin{tabular}{|} 
Extrac- \\
tif non \\
azoté
\end{tabular} & $\begin{array}{l}\text { Cen- } \\
\text { dres }\end{array}$ & $\mathrm{CaO}$ & P205 \\
\hline Fruit décortiqué, fermenté, lavé.. & Gold Coast & 4,55 & - & 45,29 & - & - & 2,39 & - & - \\
\hline- & - & 4,87 & - & 46,63 & - & - & 3,05 & - & 一 \\
\hline Fruits décortiqué, fermenté séché. & Nigéria & 4,5 & - & 46,3 & - & - & 2,5 & - & - \\
\hline Coques & Sierra Leone & 10,3 & 14,5 & 3,1 & 18,3 & 46,5 & 6,7 & - & - \\
\hline Tourteau .... & Rhodésie & 4,9 & 13,1 & 33,7 & 8,7 & 35,8 & 4,2 & - & - \\
\hline- & Tanganyika & - & 19,6 & 12,92 & 12,01 & 49,51 & 9,52 & 0,30 & 1,07 \\
\hline$\dot{-}$ & - & - & 21,72 & 14,95 & 15,21 & 39,20 & 8,89 & 0,50 & 1,53 \\
\hline
\end{tabular}

La «farine de cacao » peut contenir 2,8 p. 100 de théobromine et 1,4 p. 100 de caféine. Chez le porc, au taux de 5 p. 100 de la ration, il n'y a pas d'accidents toxiques, mais à un taux de 7,5 à 10 p. 100 des troubles apparaissent, surtout chez les vieux porcs. Le produit est peu digestible et en plus, il diminue la digestibilité de la ration à laquelle il est ajouté: une ration contenant 15 p. 100 de farine de cacao 
diminue la production laitière chez la vache, bien que la teneur en matière grasse de la ration soit augmentée; chez le veau, elle provoque de la diarrhée.

La farine obtenue avec la.graine de cacao non décortiquée et moulue, dont on a retiré 20 p. 100 de la graine, cause la mort des volailles auxquelles on l'ajoute à la pâtée dans la proportion de 10 à $30 \mathrm{p}$. 100 (cette farine renferme 1,9 p. 100 de théobromine, ce qui expliquerait les accidents), mortalité qui survient au bout d'une semaine.

Le danger de la farine disparait quand la théobromine a été extraite; on peut alors donner le produit aux jeunes porcs, à condition que l'introduction dans la ration soit progressive et que le pourcentage n'excède pas 10 p. 100 . Pour certains auteurs, le danger viendrait aussi de la présence de tanin.

Les coques, exportées vers l'Europe, y ont été assez largement employées et ont fait l'objet d'études poussées, surtout en raison des accidents qu'elles peuvent causer.

Cependant, en Gold-Coast, les « cabosses》 ne paraissent pas avoir été signalées comme toxiques. On considère que leur valeur nutritive dépasse celle des meilleurs fourrages; elles contiennent de 0,6 à 0,7 p. 100 et même 1 p. 100 de théobromine et 0,2 p. 100 de caféine; elles doivent aussi être riches en vitamine $D$; en effet l'ergostérol se développe dans la pulpe au cours de la fermentation et, pendant le séchage, se transforme en vitamine $\mathrm{D}$. Les vaches qui reçoivent, en hiver. $4 \mathrm{~kg}$ de cabosses par jour, fournissent un lait aussi riche en vitamine $\mathrm{D}$ que le lait d'été ; $100 \mathrm{~g}$ de cosses donnent environ 86 calories. D'autro part $\mathrm{l} \mathrm{kg}$ dans la ration journalière augmenterait la teneur en graisse du beurre. D'après Millot, la dose maxima tolérée est à $4 \mathrm{~g}$ par $\mathrm{kg}$ d'animal; la toxicité est donc relativement faible; il faut par ailleurs tenir compte que la torréfaction modifie la digestibilité.

$\mathrm{Si}$ on divise mécaniquement les coques de cacao grillées en fragments grossiers ou fins, les premiers ne contiennent que l'enveloppe externe, et sont moins riches en protéine et en graisses, plus riches en cellulose que les seconds. La digestibilité de la matière organique des premiers est de 42,2 p. 100 , celle des seconds de 47,3 p. 100 ; leur valeur amidon sur 90 p. 100 de matière sèche est respectivement de 36,6 et 42,5 .

Les coques importées en Europe sont utilisées après avoir été concassees, pulverisées, souvent torréfiées. Leur composition habituelle est, en

- matière sèche :

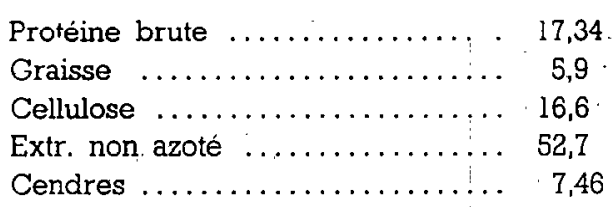

On prépare aussi des tourteaux dans lesquels elles tiennent une grande place.

L'emploi des coques a donné lieu à des interprétations très diverses. Les recherches les plus récentes montrent qu'on peut les employer chez le bouf. le mouton, le porc. Le porc, surtout jeune, paraît plus sensible que les autres animaux à la théobromine et à la caféine; il y a perte d'appétit si on dépasse 3 à 5 p. 100 de la ration peu après le sevrage.

Chez le bcuf et le mouton, les coques peuvent de façon générale remplacer le son.

Dans des essais sur des vaches laitières, on a pu donner chaque jour sans effet nocif, $0,5 \mathrm{~kg}$ à $2 \mathrm{~kg}$, la teneur du lait en matière grasse augmente, alors que la quantité de lait baisse légèrement.

\section{MÉLIACEES}

\section{Genre Melia}

Les fruits de Melia azedarach, " le lilas de Perse 》 sont parfois mangés à terre par les porcs, plus rarement par les moutons, parfois par les volailles. On sait qu'ils sont toxiques.

\section{Genre Turraeanthus}

En Afrique occidentale, les animaux mangent à terre les fruits de Turraeanthus africanus, qui pourraient être toxiques.

\section{MORACEES}

\section{Genre Artocarpus}

Ce genre (rattaché parfois aux Ulmacées - Ártocarpées) comprend une vingtaine d'espèces : arbres à pain. En Âmérique du Nord (Mexique) et du Sud (Chili) trois espèces principales sont utilisées par le bétail. On donne surtout les feuilles et pousses d'A. communis, la pulpe du fruit d'A. integrifolia, graines d'A. incisa. Cette dernière espèce, surtout, a été multipliée en diverses régions tropicales. On a conseillé au Congo belge, cette multiplication par boutures, la production de fruits 
étant abondante au bout de dix ans. La farine tirée du fruit renferme (Nigeria) :

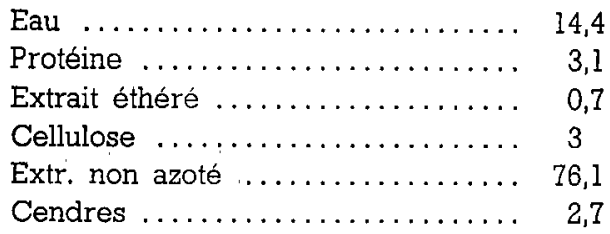

Les fruits du Jacquier, arbre à pain également, A. integrifolia, ont une composition voișine et sont aimés des animaux. Il en est de même de ceux d'A. nobilis (Ceylan).

\section{Genre Ficus}

Les figues destinées à l'alimentation humaine, sauf altération ou défauts les rendant impropres au commerce, ne sont pas données aux animaux.

Par contre, en Afrique du Nord, celles qui servent à la fabrication d'alcool laissent un résidu de distillation qui peut être donné aux divers animaux; en raison de leur teneur en alcool, mieux vaut employer ces marcs après trempage dans l'eau et égouttage. On les mélange alors au son, en les écrasant. Cela constitue une pâtée bien appétée, surtout des vaches laitières.

Quant aux fruits des divers Ficus des régions chaudes, il en est qui sont recherchés des animaux, surtout des petits ruminants, au pied des arbres, mais il est exceptionnel qu'ils soient ramassés pour être distribués. C'est ainsi que sont mangés en Nouvelles Galles du Sud les fruits de $F$. Watkinsiana, $F$. macrophylla, $F$. rubiginosa, dans l'Inde, ceux de $F$. hookeri, F. glomerata, F. religiosa, F. benghalensis, $F$. nemoralis, $F$. roxburghii, espèces parfois cultivées autour des villages, ou encore de $F$. glabella, F. macrophylla, F. ramphii. En Afrique du Sud, ceux de $F$. soldanella.

\section{Genre Morus}

Les feuilles de divers mûriers sont, nous l'avons $\mathrm{vu}$, intéressantes du point de vue fourrager. Les fruits le sont beaucoup moins. La composition des fruits de Morus alba est

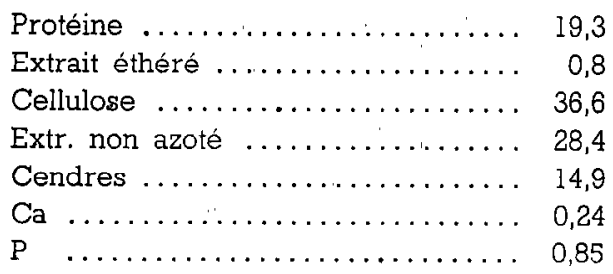

\section{MORINGACEES}

\section{Genre Moringa}

Les arbres de ce genre, asiatiques ou africains, ont des graines oléagineuses, particulièrement $M$. aptera et $M$. pterygosperma $=M$. oleifera. Elles sont traitées pour l'obtention d'une huile comestible. Le tourteau peut être donné aux animaux.

Deux analyses du fruit entier de $M$. oleifera donnent la moyenne suivante :

\begin{tabular}{|c|c|}
\hline Eau & 88 \\
\hline Protéine $\ldots \ldots \ldots \ldots \ldots \ldots \ldots$ & 20 \\
\hline Extrait éthéré $\ldots \ldots \ldots \ldots \ldots \ldots \ldots$ & 8 \\
\hline Cellulose $\ldots \ldots \ldots \ldots \ldots \ldots \ldots$ & 32 \\
\hline Extrait non azoté $\ldots \ldots \ldots \ldots \ldots \ldots$ & 35 \\
\hline Cendres . . . . . . . . & 14 \\
\hline & 0,25 \\
\hline $\mathrm{P} \ldots \ldots \ldots \ldots \ldots \ldots \ldots \ldots$ & 0,80 \\
\hline
\end{tabular}

Le tourteau de $M$. aptera renferme

Eau $\ldots \ldots \ldots \ldots \ldots \ldots \ldots \ldots, \quad 8,7$

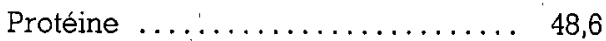

Extrait éthéré $\ldots \ldots \ldots \ldots \ldots \ldots \ldots$ 2,6

Cellulose $\ldots \ldots \ldots \ldots \ldots \ldots \ldots \ldots, 6,6$

Extrait non azoté $\ldots \ldots \ldots \ldots \ldots \ldots \ldots, 28$

Cendres $\ldots \ldots \ldots \ldots \ldots \ldots \ldots \ldots \ldots, 5,5$

Après extraction de l'huile, les graines de M. Pterygosperma laissent, d'après deux analyses :

\begin{tabular}{|c|c|}
\hline Eau .... & 8,7 et 12 \\
\hline Protéine $\ldots .$. & 57,1 et 52 \\
\hline Extrait éthéré & 0,5 et 8 \\
\hline Cellulose....... & 5,1 et 3,96 \\
\hline Extrait non azoté & 21,3 et 21,2 \\
\hline Cendres ......... & 7,3 et 3,89 \\
\hline
\end{tabular}

\section{MUSACÉES}

Les troncs de bananiers, nous l'avons vu, sont parfois utilisés dans l'alimentation animale. Les fruits également, sous des formes variées. Des diverses espèces, du genre Musa - dont le nombre est d'ailleurs susceptible de réduction - deux nous intéressent : $M$. sapientium et $M$. paradisiaca, surtout la dernière, la première étant celle qui 'va par l'exportation à l'alimentation humaine, les animaux bénéficiant des fruits insuffisants pour le commerce ou de certains sous-produits. Certaines espèces ou sous-espèces, spontanées ou cultivées, vont à la fois à l'alimentation humaine et à l'alimentation animale (bananes " cochon ").

On utilise ainsi : les bananes vertes ou mûres, les enveloppes, la farine.

Voici quelques chiffres recueillis au Congo Belge : 


\begin{tabular}{|c|c|c|c|c|c|c|}
\hline Nature & Eau & Amidon & Protéine & Graisse & Cellulose & $\begin{array}{c}\text { Hydrates } \\
\text { de Carbone }\end{array}$ \\
\hline Banane verte pelée $\ldots \ldots \ldots \ldots$ & 73,1 & - & 1,7 & 0,9 & 0,7 & 22,5 \\
\hline Banane mure pelée & 77,8 & - & 1,3 & 0,8 & 0,5 & 18 \\
\hline Cossettes de banane ......... & - & 0,16 & 3,6 & 1,3 & 一 & 70 \\
\hline Farine de bananes... & 8,5 & - & 2 & 1 & 1,7 & 82,2 \\
\hline Pelure banane verte $\ldots \ldots \ldots$ & 89,7 & - & 3,3 & - & - & $T$ \\
\hline Pelure banane mûre & 88,1 & - & 3,5 & - & - & - \\
\hline
\end{tabular}

D'autres analyses donnont les chiffres suivants :

\begin{tabular}{|c|c|c|c|c|c|c|c|}
\hline Produit & Mat. sèche & Protéine & Graisses & Cellulose & Cendres & P205 & $\mathrm{CaO}$ \\
\hline Musa paradisiaca & - & 4,63 & - & - & 4,05 & 0,32 & 0,028 \\
\hline - & 65 & 1,3 & 0,4 & 0,4 & - & - & - \\
\hline M. paradisiaca (farine) $\ldots \ldots \ldots$ & 12,3 & 2,6 & 0,4 & 0,7 & 1,8 & - & '- \\
\hline - $\quad-$ & 12,3 & 1,8 & 0,3 & 0,9 & 2,1 & - & 一 \\
\hline M. sapientium frais $\ldots .$. & 33,55 & 1,87 & 0,16 & 0,28 & 0,90 & 0,11 & 0,02 \\
\hline - & 一 & 1,5 & - & - & - & - & - \\
\hline M. sapientium (vert).. & - & 9,9 & 3 & - & - & - & - \\
\hline M. sapientium (farine). . & 14,25 & 3,06 & 0,58 & 0,60 & 2,30 & 0,03 & - \\
\hline M. sapientium (farine) $\ldots \ldots \ldots$ & 14,9 & 3,03 & 0,50 & 0.7 & 2,7 & 0,93 & 0,02 \\
\hline M. sap. vert (farine) & - & 2,88 & 0,23 & - & - & 一 & - \\
\hline- & 14,10 & 3,55 & 0,44 & 0,93 & 2,41 & 0,146 & 0,053 \\
\hline M. sap. (peau) ... & 162 & 6,1 & 8,7 & 10 & 12,1 & 0,32 & 0,35 \\
\hline
\end{tabular}

Les " peaux » provenant du traitement des fruits pour l'obtention de la farine industrielle renferment 63 p. 100 (sur matière sèche) d'extractif non azoté. 22 p. 100 de sucre total.

Ces enveloppes interviennent pour 30 à 45 p. 100 dans le poids du fruit. Vertes ou mûres, elles ont sensiblement la même composition :

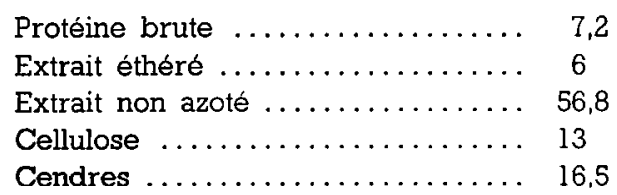

Les vitamines des " peaux 》 fraiches consistent en acide ascorbique, acide nicotinique, carotène, tocophérol, riboflavine (traces).
Les fruits non mûrs, verts, desséchés au soleil renferment :

Protéine brute $\ldots \ldots \ldots \ldots \ldots \ldots . .4,4,56$

Extrait éthéré ................. 1,24

Extrait non azoté ............. 70,21

Cellulose .................. 4,01

Cendres ................... 6,25

La farine, dont nous avons donné plus haut des analyses, offre certaines variations, ainsi que l'indiquent deux analyses du Kenya

Eau .................. 12,3 et 12,3

Protéine .............. 2,6 et 1,8

Matière grasse ........... 0,4 et 0,3

Cellulose................ 0,7 et 0,9

Extrait non azoté .......... 82,2 et 81,6

Cendres ............... 1,8 et 2,1 
On donne aux animaux, assez rarement, la banane mûre. Elle n'est particulièrement riche en aucune vitamine, mais renferme cependant en quantités appréciables les vitamines $\mathrm{B} 1, \mathrm{~B} 2$, et $\mathrm{C}$ et de petites quantités de vitamines $D$ et $E$. Aussi a-t-on pu calculer que, dans une région du Pérou où les «plantations" « Musa paradisiaca » entrent pour bonne part dans l'alimentation humaine, ces bananes fournissent à la population plus de 70 p. 100 de vitamine $A$, environ un tiers d'acide ascorbique, de vitamine $\mathrm{Bl}$ et de riboflavine, environ 15 p. 100 d'acide nicotinique. On. a observé aussi, fait intéressant pour l'alimentation animale, que la cuisson fait perdre 50 p. 100 et plus de carotène et d'acide ascorbique.

On donne aussi aux animaux, particulièrement aux porcs, les « bananes-légumes », les bananes vertes appartenant à des régimes avortés ou ne répondant pas aux caractéristiques exigées par le commerce, $A$ ce stade, le fruit est moins nutritif, l'amidon ne s'étant pas encore transformé en sucre. Il est moins nutritif aussi que les céréales et le manioc. Il pourrait même être nuisible, ainsi que le montreraient les expériences sur le cobaye; les accidents pourraient être dus à la carence en vitamine $\mathrm{C}$.

La farine est obtenue avec les bananes mûres ou les bananes vertes. La fabrication est assez difficile avec les fruits bịen mûrs. L'état de maturité fait évidemment varier la composition. C'est ainsi que, à côté des chiffres cités plus haut, une autre analyse donne 4,9 p. 100 de protéine, et une deuxième :

$\begin{array}{lr}\text { Proteine brute } \ldots \ldots \ldots \ldots \ldots \ldots \ldots \ldots & 3,55 \\ \text { Extrait éthéré } \ldots \ldots \ldots \ldots \ldots \ldots \ldots \ldots & 0,44 \\ \text { Cellulose } \ldots \ldots \ldots \ldots \ldots \ldots \ldots \ldots & 0,93 \\ \text { Extractif non azoté } \ldots \ldots \ldots \ldots \ldots \ldots & 78,41 \\ \text { Cendres } \ldots \ldots \ldots \ldots \ldots \ldots \ldots \ldots & 2,41\end{array}$

Elle renferme une diastase, l'amylase qui peut intervenir dans la digestion des hydrates de carbone, de la vitamine $B l$, peu ou pas de vitamine $C$.

La farine de bananes peut être remplacée par les bananes, séchées au soleil, en fragments qui se digèrent moins bien que la farine. On a utilisé ces produits surtcut chez les porcs, les volailles. On y a eu recours, en 1941, en Hollande, pour alimenter les porcs en remplacement du maïs. C'est aussi à cette substitution qu'on a recours chez les volailles; mais ce n'est pas favorable, même si on compense la pauvreté du produit par l'addition de soja ou de farine de poisson.

On a aussi essayé la farine déshydratée chez le veau, dans des proportions de 5 à 40 p. 100 de la ration pour juger de son effet sur la croissance et la. prévention de la diarrhée. La ration est mieux eppétée, la diarrhée est moins sévère, la croissance ne paraît pas influencée.
Dans les pays de production on donne souvent avec les fruits les tiges et les feuilles. Rappelons que la teneur en eau varie de 72,45 à 95,51 p. 100 , la moyenne étant de $2,7 \mathrm{p}$. 100 pour les protéines, 0,7 p. 100 pour les graisses, 7,1 p. 100 pour l'extractif non azoté, 4 p. 100 pour la cellulose. L'équivalentamidon est de 14,1 et les unités nutritives de 20,5 pour $100 \mathrm{~kg}$.

\section{MYRICACEES}

\section{Genre Myrica}

Les arbres ou arbustes de ce genre se rencontrent dans les régions chaudes comme dans les régions tempérées. Les fruits de certaines espèces ont une enveloppe qui renferme une substance cireuse utilisée par l'industrie. Ces fruits, løur résidu, peuvent être donnés aux animaux (M. cordifolia en Amérique du Sud, $M$. cerifera ( $=M$. pensylvanica) en Amérique du Nord). Les derniers ont la composition moyenne suivante :

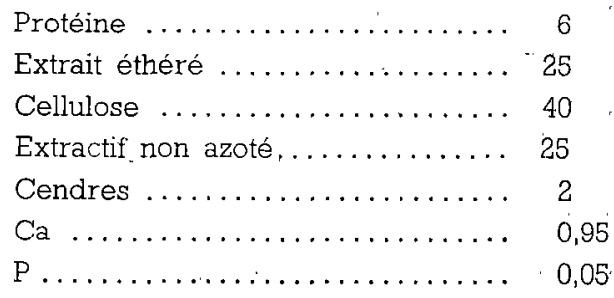

\section{OCHNACÉES}

\section{Genre Lophira}

Le tourteau des graines de Lophira alata, d'Afrique occidentale, renferme 11,69 p. 100 de proténe, 4,48 de cendres ( $\mathrm{CaO}, 0,18 ; \mathrm{P} 2 \mathrm{O}, 0,51$ ).

\section{Genre Ochna}

Les fruits que portent les espèces de ce genre sont des baies qui sont intéressantes par le péricarpe et le noyau. Elles fournissent une huile alimentaire; après extraction, le résidu a une composition variable selon qu'on a traité le fruit entier, ou le péricarpe, ou l'amande. Les tourteaux de fruits d'Ochna pulchra, d'Afrique du Sud et orientale contiennent : :

\begin{tabular}{|c|c|c|c|}
\hline & Fruit entier & Noyau & Péricarpe \\
\hline$\ldots \ldots \ldots \ldots \ldots \ldots$ & 11,7 & 10,3 & 10,3 \\
\hline Protéine.............. & 14,5 & 21,3 & 7,5 \\
\hline xtrait éthéré . . . . . . & 0,8 & 0,9 & 0,5 \\
\hline Cellulose $\ldots . \ldots \ldots$ & $11,4 \cdots$ & 2,1 & 18,8 \\
\hline xtractif non azoté....... & 59,4 & $69,3^{\prime}$ & 68 \\
\hline endres $\ldots \ldots \ldots \ldots \ldots$ & 2,1 & 2,2 & 2,3 \\
\hline
\end{tabular}




\section{OLACACÉES}

Genre Ximenia

Deux espèces africaines du genre (parfois confondues) ont des fruits que le bétail mange volontiers : $X$. americana, "olive sauvage " de l'Afrique méridionale, orientale et occidentale et et $X$. caffra, d'Afrique méridionale et orientale.

Le noyau du fruit de Ximenia americana est riche en huile :

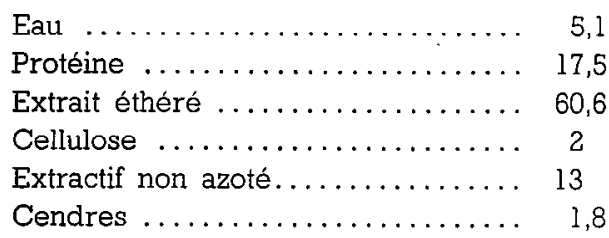

Après extraction de l'huile, on obtient un tourteau dont la farine a la composition suivante (trois analyses, Afrique du Sud et Afrique orientale): Eau $\ldots \ldots \ldots \ldots \ldots \ldots \ldots \ldots, \quad 6,2 \quad 7,2 \quad 7,5$ Protéine............... 38,8 41,5. 41,3 Extrait éthéré $\ldots \ldots \ldots \ldots \ldots .6 \%$ 5,3 $5 \quad 1,6$ Cellulose $\ldots \ldots \ldots \ldots \ldots \ldots .6,6,3 \quad 8,9 \quad 6,1$ Extractif non azoté......... $13 \quad 38,1 \quad 31,3$ Cendres ............... 5,3 6,1 5,5

\section{OLEACÉES}

Arbustes ou arbres de l'Inde, d'Australie, d'Afrique, les diverses espèces du genre voient leurs feuilles recherchées du bétail, à tel point qu'on a recommandé la multiplication de certaines (O. verrucosa var. africana). Bien que les fruits aient, pour certaines, l'aspect de ceux de l'olivier commun, il ne semble pas qu'on en ait fait usage pour les animaux. Par contre, les olives ordinaires fruits d'Olea europaea (O. odorata). jouent un rôle parfois intéressant dans l'alimentation des animalix. particulièrement en Afrique du Nord.

Les animaux reçoivent rarement les olives ellesmêmes, mais la pulpe épuisée, les noyaux; les " grignons " sont constitués par le noyau et la pulpe du fruit après extraction. Bruts, ils renferment à peu près autant de pulpe que de noyaux.
L'analyse d'olives fraîches, sèches ou en saumure donne les résultats suivants :

\begin{tabular}{|c|c|c|c|}
\hline & $\begin{array}{l}\text { Fraiches } \\
18665\end{array}$ & $\begin{array}{l}\text { Sêches } \\
5685\end{array}$ & En saumure \\
\hline roté & 2,36 & 3.94 & 3,36 \\
\hline end & 2,76 & 11,01 & 6,66 \\
\hline latière sèche & 29,24 & 75,32 & 42,12 \\
\hline
\end{tabular}

La teneur de l'huile en carotène est respectivement de $2,24,9,44$ et $7,1 \mathrm{mg}$ par $\mathrm{g}$.

Les " grignons " épuisés par les solvants renferment encore :

Protéine digestible $\ldots \ldots \ldots$
Graisse $\ldots \ldots \ldots \ldots \ldots \ldots$
Extractif non azote...........

Composition voisine de celles des grignons bruts, sauf la teneur en matière grasse.

Ces sous-produits sont surtout utilisés chez le porc. Ils sont assez altérables, surtout les pulpes non déshuilées. Ils peuvent alors devenir dangereux On pourrait éviter les altérations én ensilant avec 5 p. 100 de sel et en tassant fortement.

On admet qu'il faut $300 \mathrm{~g}$ de grignons épuisés pour remplacer $200 \mathrm{~g}$ de grain. Le's grignons frais sans noyaux remplacent dans les proportions de 2 pour 3 le son chez des vaches laitières. Chez le porc, $150 \mathrm{~kg}$ de grignons vierges et $165 \mathrm{~kg}$ de grignons épuisés pourraient remplacer $120 \mathrm{~kg}$ de farine de maïs.

\section{OMBELLIFÈRES}

Les graines de Trapa bispinosa, la " noisette d'eau " sont parfois utilisées pour l'obtention d'une farine qui, dans linde, a la composition suivante :

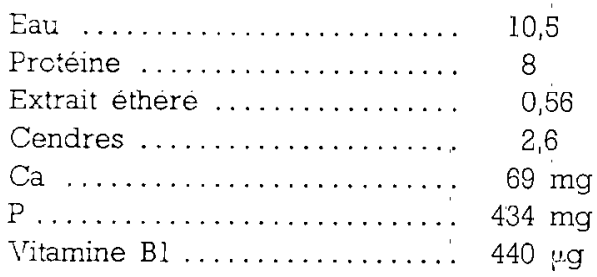

L'experimentation montre quc la protéine de cette farine a une valeur biologique supérieure à celle de la protéine du blé et d'autres céréales. 